\title{
Moral Hazard in Active Asset Management
}

\author{
David C. Brown ${ }^{\mathrm{a}, *}$, Shaun William Davies ${ }^{\mathrm{b}}$ \\ ${ }^{a}$ Eller College of Management, University of Arizona, McClelland Hall, Room 315R, P.O. Box 210108, Tucson, \\ AZ 85721-0108, USA \\ ${ }^{b}$ Leeds School of Business, University of Colorado, Boulder, Campus Box 419, Boulder, CO 80309, USA
}

\begin{abstract}
We consider a model of active asset management in which mutual fund managers exert unobservable effort to earn excess returns. Investors allocate capital to actively managed funds and passively managed products. In equilibrium, investors are indifferent between investing an additional dollar with an active manager or with a passively managed product. As passively managed products become more attractive to investors, active managers' revenues from portfolio-management services fall, reducing their effort incentives. More-severe decreasing-returns-to-scale are also associated with reduced incentives and increased moral hazard. Performance-based fees and holdings-based data are all unlikely to mitigate moral hazard.
\end{abstract}

JEL classification: G11

Keywords: Mutual Funds, Moral Hazard, Active Management, Passive Management

\section{Introduction}

A large literature is devoted to evaluating the performance of active mutual funds, and in particular, attempting to identify skilled managers. ${ }^{1}$ For example, recent research by Berk and van

\footnotetext{
${ }^{\text {th }}$ We would like to thank Vincent Glode, Neal Stoughton, Rick Green, Luke Taylor, Martijn Cremers, Simon Gervais, Wei Li, Youchang Wu, Ryan Williams, Chris Leach, Bruce Carlin, Rick Sias, Aazam Virani, Rob Dam, Tony Cookson, Ed Van Wesep, Jason Lunn, Nathalie Moyen, Sergei Kovbasyuk, Scott Cederburg, Mathias Kronlund, Kevin Crotty, Diego García, an anonymous referee and seminar participants at the UBC Summer Finance Conference, 13th Paris December Finance Meeting, Midwest Finance Association Annual Meeting, the 2016 ITAM Finance Conference, the University of Colorado, the University of Arizona and the Einaudi Institute of Economics and Finance for their helpful insights and suggestions.

*Corresponding author. Tel.: +1 520-621-0746; fax: +1 520-621-4261

Email address: dcbrown@email.arizona.edu (David C. Brown)

${ }^{1}$ For examples, see Jensen (1968), Carhart (1997), Daniel, Grinblatt, Titman, and Wermers (1997), Kacperczyk, Sialm, and Zheng (2005, 2008), Baker, Litov, Wachter, and Wurgler (2010), Fama and French (2010), Del Guercio
} 
Binsbergen (2015) provides evidence that asset managers are persistently skilled, and estimates that the average manager adds value of $\$ 3.2$ million per year. Interestingly, while about half is attributable to stock picking and market timing skill, the other half of the value added is attributable to providing diversification services. Given the large value associated with simply providing diversification services, what motivates managers to exert the effort required to pick stocks or time the market?

Motivated by this question, we model the moral hazard problem faced by active asset managers. Our model relies on two innovations to the classic asset management model of Berk and Green (2004). First, we assume managers are better informed about their abilities to generate excess returns. Incorporating information asymmetry is consistent with recent work by Berk, van Binsbergen, and Liu (2014), which shows fund families are more informed about managers' abilities than are outside investors. Second, rather than focusing on a single fee, fees collected on assets under active management (AUM) are decomposed into two components: (i) a fee for the portfolio management service (which we coin the passive fee) and (ii) a fee for active asset selection (coined the active fee). Intuitively, the passive fee is equal to what investors would pay for a passively managed product that provides only diversification services.

In the model, a universe of fund managers supplies active asset selection and portfolio management over two periods. Managers privately observe their types and also choose whether or not to expend costly research effort. Managers who expend effort (truly active funds) expect positive abnormal returns, and expectations are increasing in skill. Managers who shirk (faux-active) earn zero expected abnormal returns. As in Berk and Green (2004), Pástor and Stambaugh (2012), and Brown and $\mathrm{Wu}$ (2014), we also assume funds face decreasing-returns-to-scale and investors competitively allocate capital. Thus, because investors are rational, they collectively invest in each fund until the expected return (net of fees) on the last dollar is equal to the expected return on their outside option - a passive investment which produces the market return minus the passive fee.

Initially, without a means to identify truly active or highly skilled funds, investors allocate equal AUM to all funds. After observing performance in the first period, investors' update their beliefs

and Reuter (2014) and Kacperczyk, Van Nieuwerburgh, and Veldkamp (2014), among others. 
and reallocate AUM. As abnormal returns signal a fund's effort and type, successful funds gain AUM while unsuccessful funds lose AUM. The resulting second-period AUM gap — and corresponding revenue gap - provides an incentive for managers to exert effort. In equilibrium, the AUM gap and managers' effort choices are jointly determined. Managers adhere to a threshold rule with respect to their skill; managers above the threshold choose to pursue truly active strategies and managers below it shirk. The threshold, which serves as a sufficient statistic for the severity of the moral hazard conflict (a higher threshold is associated with more severe moral hazard), is driven by several forces in our model.

First, the passive fee is negatively related to the threshold; as investors' outside opportunities in passive products improve, the rents associated with active management shrink. In contrast to the active fee, the passive fee does not enter the expression for a fund's AUM. However, it does enter into a manager's revenue calculation. Falling fees decrease managers' revenues, reducing their incentives to exert effort. Thus, lower passive management fees are associated with greater moral hazard.

Second, the threshold level is increasing in the severity of decreasing-returns-to-scale. When decreasing-returns-to-scale become more severe, perhaps due to increasing industry competition, e.g., see Pástor, Stambaugh, and Taylor (2015), managers less efficiently deploy capital. As a result, following abnormal returns, successful managers receive smaller increases in capital. In the opposite scenario, unsuccessful managers are not punished as harshly, as subsequent positive abnormal returns are more likely from a smaller asset base. More-severe decreasing-returns-to-scale dampen the AUM gap, and as a result, decrease effort incentives.

Several other factors also influence moral hazard in our model. Most clearly, higher costs of effort lead to a higher threshold and more moral hazard. Potential abnormal returns and active fees impact managers' incentives through the AUM gap. However, the effects are parameter dependent and sensitive to modeling assumptions, so we leave a detailed discussion of these results to Section 2.

While we are agnostic regarding welfare implications, greater shirking reduces the effective effort of truly active funds via two channels. The direct effect is obvious: greater shirking implies fewer funds exert effort. Indirectly, greater shirking leads to less AUM for all funds, so truly active funds' efforts are less effective as they are applied to smaller asset bases. The indirect effect highlights that small increases in shirking can have large aggregate impacts on industry excess returns. 
Our modeling choices allow us to study moral hazard in the presence of adverse selection, but also limit our ability to allow funds to separate from lower types or shirkers. Consistent with the approach of Cuoco and Kaniel (2011), and supported by evidence of a historically flat fee structure (Christoffersen, 2001), we restrict funds to offer identical contracts. We further assume that managers are ex ante identical to investors. ${ }^{2}$ In this setting, we consider how moral hazard interacts with standard features of the mutual fund contracting environment. ${ }^{3}$ First, we consider the effect of a performance-based fee, referred to as a fulcrum fee, on a fund manager's incentive to be truly active. If the performance-based fee is sufficiently low there is less moral hazard. The intuition is straightforward: by forcing the fund manager to more directly internalize his effort decision, the agency conflict is partially mitigated. However, if the performance-based fee is sufficiently large, there is greater moral hazard. By transferring a large share of excess returns to the manager, investors are crowded out and AUM shrinks. Lower AUM reduces the benefit of effort and more shirking ensues. This result highlights that excessive performance-based fees can exacerbate moral hazard in active asset management.

Second, we consider holdings-based measures of a manager's effort choice: does he hold the benchmark or is he making active bets? While measures such as Active Share (Cremers and Petajisto, 2009) attempt to link holdings to fund activity, funds may anticipate investors' use of

\footnotetext{
${ }^{2}$ In an internet appendix, we extend the model to a setting in which managers costlessly communicate their types, eliminating asymmetric information. While one interpretation of a fully separating equilibrium may result from a more complicated signaling model, we study the extreme case to show our result is robust to eliminating all asymmetric information about manager skill. Even when funds separate and their types are known, moral hazard is still present. Managers optimally mix between being truly active and shirking, leading to similar results as in our base model. In fact, the directions of the comparative statics are unchanged from our main results, showing that eliminating asymmetric information regarding managers' skills does not eliminate moral hazard.

${ }^{3}$ Given the partial-equilibrium nature of our model, we do not emphasize an optimal contract. See García and Vanden (2009) and Buffa, Vayanos, and Woolley (2014) for analyses considering optimal contracting in delegated investment management. Because investors always break even, total surplus in our model depends only on the value captured by asset managers. To maximize managers' surplus, the active fee would be set to zero, leading to infinite AUM and infinite manager rents (provided the passive fee is positive). However, in such a scenario, the probability of producing abnormal returns is zero and no effort is exerted - the active management industry would be entirely passive. As we do not model any social welfare to efficient prices, such an optimal contract cannot be taken too seriously.
} 
such measures and adjust their own holdings in response. Accordingly, we extend our model to accommodate shirking managers' abilities to choose portfolio variance strategically, i.e., to inject noise into the signal. Intuitively, shirking managers inject noise into their holdings and returns in order to cloud investors' inferences. Noise injection and shirking are complements; as the moral hazard problem becomes more severe, faux-active managers inject more noise, attenuating investors' abilities to identify skilled managers. Our result suggests that signals of moral hazard based on holdings or tracking error may be less effective in the future as shirking managers adapt their strategies to avoid detection.

Our analysis is most directly related to Berk and Green (2004). A key difference is that in our model, fees matter. In Berk and Green (2004), due to competitive investor capital and the managers' abilities to benchmark excess capital, fees become irrelevant. Managers are indifferent between large AUM with a small fee, or small AUM with a large fee. In our model, managers also enjoy rents from providing diversification services. As a result, all else equal, managers would prefer high AUM and correspondingly high passive management revenues.

Our main contribution is to provide an analysis of moral hazard in active asset management. By maintaining many of the key assumptions of classic models, simplifying the returns process, and incorporating both adverse selection and the separation of fees for asset selection and diversification services, we are able to provide new insights. In particular, we link passive and active asset management, showing that innovations in passive investing that reduce passive fees also reduce active managers' incentives to increase AUM by outperforming benchmarks, exacerbating moral hazard. Additionally, forces that reduce the sensitivity of AUM to performance, for example, more severe decreasing-returns-to-scale, also increase moral hazard. Performance-based fees and holdings-based measures are unlikely means to reduce moral hazard.

\section{Base model}

Consider a two-period model in which there exists a set of actively managed funds and an infinite number of investors. Each fund is run by a risk-neutral manager whose objective is to maximize net payoff. A fund's gross profit is determined through a price channel (management fee) and a quantity channel (assets under management). Actively managed funds supply two services to investors: (i) portfolio management (diversification) and (ii) active asset selection. Investors 
are competitive and allocate their capital to equate the expected benefit (i.e., excess return) and cost (management fee). The assumption of perfectly elastic investor capital is commonplace in the delegated portfolio management literature (see, e.g., Berk and Green, 2004; Pástor and Stambaugh, 2012; Brown and $\mathrm{Wu}, 2014)$. The discount rate between periods is normalized to zero.

Each fund's manager has a private skill type $\theta$ that is drawn from the unit continuum $[0,1]$. The managerial skill types are individually and identically distributed according to a continuous and strictly positive probability density function $g(\tilde{\theta})$,

$$
\theta \sim g(\tilde{\theta})
$$

which has the cumulative density function $G(\tilde{\theta})$. A manager's skill corresponds to his fund's ability to earn excess returns; a high draw of $\theta$ implies a greater ability to earn excess returns than a low draw. This is expounded on shortly. Skill types are privately observed and cannot be credibly disclosed.

A fund's ability to earn excess returns is also influenced by whether or not the fund exerts costly effort. Funds that choose to exert effort incur an incremental effort cost,

$$
c>0
$$

which is not observable to investors. The funds that incur $c$ are defined as truly active managed funds (characterized by the subscript $A$ ). The funds that do not incur the cost are defined as faux-active funds (characterized by the subscript $A$ ).

A fund that exerts costly effort achieves a distribution of excess returns (relative to its unmodeled benchmark) that first-order-stochastically dominates the excess return distribution without effort. This feature is captured simply by allowing funds that pay $c$ the chance to earn excess returns (i.e., alpha),

$$
\alpha>0
$$

in each period. We implicitly assume that effort is long-lived. Our results are qualitatively unchanged so long as effort does not decay entirely in a given period. The parameter proxies for the excess returns that are obtainable via active management. All excess returns flow through to investors and the market return is normalized to zero. We also assume managers are restricted from borrowing capital beyond that provided by investors (a common restriction in mutual funds). 
A truly active fund's ability to earn $\alpha$ is influenced by its manager's skill and the elasticity of excess returns relative to assets under management (AUM). The elasticity parameter is denoted

$$
\eta>0
$$

The parameter $\eta$ captures the notion that truly active funds experience decreasing-returns-toscale. Decreasing-returns-to-scale is a common assumption in asset management models (see, e.g., Berk and Green, 2004; Pástor and Stambaugh, 2012). Furthermore, inclusion of the parameter is supported by empirical evidence (see, e.g., Chen et al., 2004; Fung et al., 2008; Pollet and Wilson, 2008; Hoberg et al., 2016; Pástor et al., 2015). A parameter of $\eta$ near zero (near $\infty$ ), represents almost perfectly inelastic (elastic) excess returns with respect to AUM. The parameter is related to the scalability of a fund's strategy and to the level of competition within the fund's strategy space. We do not directly model trading costs. However, the parameter $\eta$ indirectly captures them.

Each fund in the truly active space $A$ earns $\alpha>0$ in period $t \in\{1,2\}$ with a probability that is determined by its manger's skill, the fund's elasticity parameter, and the fund's assets under management at $t$. Namely, the probability of success $(S)$ is given by,

$$
\operatorname{Pr}\left(S \mid \theta, K_{t}, \eta, A\right) \equiv \frac{\theta}{1+\eta K_{t}}
$$

where $K_{t}$ is the fund's AUM at $t$. The expression in Eq. (5) requires that the fund is truly active, i.e., the fund has incurred effort $\operatorname{cost} c$. For simplicity, the probability that a faux-active fund earns $\alpha$ is equal to zero but that assumption is relaxed in Section 4. The probability in Eq. (5) is increasing in $\theta$, and decreasing in both $K_{t}$ and $\eta$. That is, a high-type fund expects more excess returns ex ante than a low-type fund. Furthermore, the probability of earning excess returns is diminishing in the product of the fund's AUM and the parameter $\eta{ }^{4}$

If a fund successfully earns $\alpha$, investors observe it directly through the fund's performance because all excess returns are captured by the fund's investors. Conversely, if a fund does not earn $\alpha$, investors cannot distinguish whether the fund was truly active and failed or if it never undertook

\footnotetext{
${ }^{4}$ In our model, a fund's value added (the probability of success times AUM) is increasing in AUM, but at a decreasing rate. While our model features decreasing-returns-to-scale, it does not produce an internal optimum for a fund manager's active assets as in Berk and Green (2004). As a result, non-shirking managers would never optimally benchmark a portion of their assets.
} 
costly effort in the first place. Investors' inability to observe if a fund incurred $c$ lends plausible deniability to the funds that do not succeed. We assume that investors are only able to observe fund performance and not other fund characteristics such as holdings. In Section 4, we allow managers to influence expected returns through effort, and influence the variance of returns (i.e., tracking error) through portfolio construction.

Investors also have access to a universe of passively managed products. Passively managed products (e.g., index funds and exchange traded funds (ETFs)) supply only the portfolio management service to investors, i.e., they allow investors to earn market returns in a well-diversified portfolio. By definition, passive products provide the market return net of a management fee,

$$
F_{P}>0
$$

Each active fund, whether truly active or faux-active, charges an incremental fee above $F_{P}$,

$$
F_{E}>0
$$

in exchange for active asset selection. As such, the total management fee charged by an active fund is $F_{E}+F_{P}$. We refer to $F_{E}$ as the active fee and $F_{P}$ as the passive fee. The management fee is sticky and does not change between periods one and two.

Investors are competitive and collectively allocate their capital in each of the two periods so that the expected net benefit of investment in each fund is equal to investing in a passive product. Investors are rational and have accurate beliefs about the funds. As such, at $t=1$, investors allocate their capital according to their initial beliefs. At the conclusion of that period, excess returns are realized (or not) and passed through to investors. Investors subsequently update their beliefs about each fund and, at the beginning of $t=2$, reallocate their capital based on their refined beliefs. The model's timing is summarized in Fig. 1.

Investors' indifference between investing in an active fund or their outside option of a passive product yields the condition:

$$
\left(1-F_{P}\right)=\left(1-F_{E}-F_{P}+\alpha \operatorname{Pr}\left(S_{1} \mid K_{1}, \eta\right)\right)
$$

where $\operatorname{Pr}\left(S_{1} \mid K_{t}, \eta\right)$ is the probability of success that investors assess to the fund based on their beliefs. The left-hand side of Eq. (8) is the net return on the passive product and the right-hand 
side is the net return on an actively managed product. Investors allocate capital until the net returns are equal. Similarly, investors reallocate their capital at $t=2$ based on their refined beliefs,

$$
\left(1-F_{P}\right)=\left(1-F_{E}-F_{P}+\alpha \operatorname{Pr}\left(S_{2} \mid K_{2}, \eta, \mathbb{1}_{S_{1}}\right)\right)
$$

where $\mathbb{1}_{S_{1}}$ is an indicator function that equals one if the fund succeeded in earning excess returns at $t=1$ and equals zero otherwise. For clarity, define the following shorthand notation,

$$
\begin{aligned}
\operatorname{Pr}\left(S_{1}^{\star}\right) & \equiv E[\theta \mid A], \\
\operatorname{Pr}\left(S_{2}^{\star} \mid \mathbb{1}_{S_{1}}\right) & \equiv E\left[\theta \mid \mathbb{1}_{S_{1}}, A\right] .
\end{aligned}
$$

The preceding notation implies,

$$
\begin{array}{r}
\operatorname{Pr}\left(S_{1} \mid K_{1}, \eta, A\right)=\frac{\operatorname{Pr}\left(S_{1}^{\star}\right)}{1+\eta K_{1}}, \\
\operatorname{Pr}\left(S_{2} \mid K_{2}, \eta, A\right)=\frac{\operatorname{Pr}\left(S_{2}^{\star} \mid \mathbb{1}_{S_{1}}\right)}{1+\eta K_{2}} .
\end{array}
$$

The following lemma utilizes the expressions in Eqs. (8) and (9) to define the capital allocation rule for the fund in each period.

Lemma 1. A fund's capital allocations in periods 1 and 2 are given by,

$$
\begin{aligned}
K_{1} & =\max \left\{\frac{\alpha \operatorname{Pr}\left(S_{1}^{\star}\right)-F_{E}}{\eta F_{E}}, 0\right\}, \\
K_{2}\left(\mathbb{1}_{S_{1}}\right) & =\max \left\{\frac{\alpha \operatorname{Pr}\left(S_{2}^{\star} \mid \mathbb{1}_{S_{1}}\right)-F_{E}}{\eta F_{E}}, 0\right\} .
\end{aligned}
$$

The comparative statics of the capital allocation in Lemma 1 are straightforward: investors allocate more capital to a fund when possible excess returns $\alpha$ are large, when the incremental fee $F_{E}$ is low, and when the parameter $\eta$ is small. The lemma also dictates that the capital allocations are increasing in the investors' beliefs about the manager's skill $\theta$. Furthermore, the results of Lemma 1 imply that $F_{E}$ is restricted to the interval $[0, \alpha]$ without loss of generality; if $F_{E}$ exceeds $\alpha$, capital allocations are surely equal to zero.

It is also important to note that $F_{P}$ does not appear in Eq. (14) or Eq. (15). Investors pay $F_{P}$ whether they use an actively managed fund or a passively managed fund. As such, capital allocations are driven entirely by expected excess returns and the incremental fee $F_{E}$ above $F_{P}$. The passive fee $F_{P}$, however, does affect funds' net payoffs. Active managers extract rents for the portfolio management service even though it does not enter investors' capital allocations. 
Each fund's gross profit is determined by the total management fee $F_{E}+F_{P}$ and the amount of capital it attracts. ${ }^{5}$ Denote a fund's net payoff as $\Pi_{j}$,

$$
\Pi_{j}\left(\mathrm{a}_{j}\right)= \begin{cases}\left(F_{E}+F_{P}\right)\left(K_{1}+K_{2}(0)\right) & \text { if } \mathrm{a}_{j}=A \\ \left(F_{E}+F_{P}\right)\left(K_{1}+K_{2}\left(\mathbb{1}_{S_{1}}\right)\right)-c & \text { if } \mathrm{a}_{j}=A,\end{cases}
$$

where $\mathrm{a}_{j}$ represents fund $j$ 's choice to be $A$ or $A$.

The competition among investors implies that each fund captures all expected excess returns (from an investor's perspective). Each fund captures the expected excess returns via fund flows (changes in quantity) because the fee (price) is fixed - this is a point highlighted by both Berk and Green (2004) and Pástor and Stambaugh (2012). As just discussed, each fund's gross profit also includes the rents associated with delegated portfolio management via the passive fee. Consequently, there are two gross profit components: expected excess returns (from an investor's perspective) and the cumulative value of delegated portfolio management. "From an investor's perspective" is emphasized because investors' beliefs about expected excess returns and a fund's beliefs are almost certainly different. The presence of adverse selection, which is discussed in detail shortly, implies that high (low) type funds believe that excess returns will be larger (smaller) than investors do. In Section 3, this mismatch of beliefs is addressed by allowing funds to charge a performance-based fee and retain a portion of excess returns.

A fund's choice to be a truly active fund or faux-active fund is endogenous. We analyze this choice by first defining $\Delta(\theta)$ as a benefit-cost function for a fund with type $\theta$,

$$
\begin{aligned}
\Delta(\theta) & \equiv \Pi_{j}(A \mid \theta)-\Pi_{j}(A \mid \theta), \\
& =\frac{\theta\left(F_{E}+F_{P}\right)}{1+\eta K_{1}}\left(K_{2}(1)-K_{2}(0)\right)-c .
\end{aligned}
$$

Recalling that $K_{2}(1)$ is the second-period capital following first-period success and $K_{2}(0)$ is the capital following failure, the function $\Delta(\theta)$ compares a fund's expected payoffs if it chooses to be a truly active fund relative to the fund's expected payoffs if it chooses to be a faux-active fund. It is clear from Eq. (18) that the benefit of being truly active is increasing with the separation that occurs at $t=2$, which is the quantity

$$
K_{2}(1)-K_{2}(0)
$$

\footnotetext{
${ }^{5}$ For tractability, fees are earned on beginning-of-period assets under management.
} 
Highlighting the benefit of separation is useful in understanding the model's tensions. The function in Eq. (18) is weakly increasing in $\theta$ and $\Delta(0)<0$. If $\Delta(1)>0$, there exists some fund type $\theta \in(0,1)$ for which the fund is indifferent between being a truly active fund or a faux-active fund. The following lemma formalizes the intuition.

Lemma 2. There exists a unique equilibrium in which a fund chooses whether or not to incur effort cost c according to a threshold,

$$
\theta^{*} \in(0,1]
$$

A fund with type $\theta<\theta^{*}$ chooses to not incur effort cost $c$ and is a faux-active fund $(A)$. A fund with type $\theta \geq \theta^{*}$ chooses to incur effort cost $c$ and is a truly active fund (A).

According to Lemma 2, investors face two agency conflicts when they choose a fund manager. The first is adverse selection, which is exogenous in the model. Conditional on choosing a fund that exerts effort, an investor cannot distinguish if the fund is marginal (i.e., a type near $\theta^{*}$ ) or superior (i.e., a type near 1). The second is moral hazard, which arises endogenously. Investors cannot distinguish between the funds that are exerting costly effort and the ones that masquerade as if they are. Indeed, an investor choosing a fund will fall prey to moral hazard with probability $G\left(\theta^{*}\right)$. For the remainder of the analysis, the threshold itself is considered, as it is a sufficient statistic for the fraction of funds that are faux-active and the severity of the moral hazard problem.

Proposition 1. The threshold $\theta^{*}$ is

(i) decreasing in $F_{P}$,

(ii) increasing in $c$,

(iii) increasing in $\eta$.

The comparative statics of $\theta^{*}$ with respect to $F_{E}$ and $\alpha$ are equivocal.

According to Proposition 1, decreasing the passive fee increases $\theta^{*}$, which corresponds to increased moral hazard. Because $F_{P}$ does not affect a fund's AUM, but does affect a manager's revenue per dollar of AUM, decreasing $F_{P}$ reduces effort incentives by making abnormal returns less profitable. Thus, innovation in the passive managed product space has a spillover effect in 
active management via $F_{P}$. As the fees associated with products like index funds and ETFs fall, the incentive to actively manage a portfolio also falls.

Proposition 1 also provides a full characterization of $\theta^{*}$ with respect to the model's other exogenous parameters. The comparative static with respect to $c$ is natural: one would expect the fraction of faux-active funds to increase with the cost of being truly active. The comparative static with respect to $\eta$ is less obvious.

The fraction of faux-active funds increases in $\eta$ as excess returns become more sensitive to AUM (due to increased competition or reduced strategy capacity). The result is best understood by considering a fund-flow hedging effect associated with $\eta$, and its corresponding effect on the separation that occurs at $t=2$. If a fund succeeds at $t=1$, investors update their beliefs upward and more capital flows into the fund. Capital inflows, however, have an adverse effect on expected excess returns because an increase in AUM decreases the probability of success due to $\eta$. Consequently, flows to the fund are dampened. Similarly, if a fund fails at $t=1$, investors update their beliefs downward and capital flows from the fund. Capital outflows have a positive effect on expected excess returns because a decrease in AUM increases the probability of success via $\eta$. Again, flows from the fund are dampened. Consequently, $\eta$ hedges fund-flow volatility and necessarily dampens the spread $K_{2}(1)-K_{2}(0)$. Larger values of $\eta$ result in more hedging, decreasing separation at $t=2$ and the benefit of being truly active.

Finally, the relations between $\theta^{*}$ and the parameters $\alpha$ and $F_{E}$ are ambiguous. On the one hand, increasing $\alpha$ or decreasing $F_{E}$ increases the spread $K_{2}(1)-K_{2}(0)$, all else equal. The larger spread makes exerting costly effort more attractive. On the other hand, a larger $\alpha$ or smaller $F_{E}$ implies a larger initial asset base $K_{1}$. Because the probability of successfully achieving excess returns is diminishing in $K_{1}$, managers do not find exerting effort as attractive. Which effect dominates is parameter dependent.

Our ambiguous results are a function, and potential weakness, of our modeling assumptions. Our model features decreasing-returns-to-scale which are never negative. That is, expected excess returns asymptotically approach zero as AUM increases. Accordingly, new assets allocated to a fund always add value, but at the expense of increasing the probability that the fund will fail to differentiate itself through abnormal returns. Given that canonical models, e.g., Berk and Green (2004), feature the possibility of negative returns, we feel it is important to downplay the 
comparative statics with respect to $\alpha$ and $F_{E}$.

While we remain agnostic towards the externalities imposed on the market by managers' shirking, increased shirking negatively impacts the effective effort of truly active funds in two ways. First, the direct effect is that an increase in shirking reduces the number of funds exerting effort. The previously marginal fund that was exerting effort no longer is, so total effort decreases. Second, the indirect effect is that investors react to a larger portion of faux-active funds by reducing their investment. All funds initially receive less capital, and the truly active funds' effort is less effective as it is applied to fewer assets. Through both direct and indirect channels, increased shirking reduces the effectiveness of truly active management.

\subsection{Performance-flow sensitivity}

The model of Berk and Green (2004) demonstrates that the evolution of investors' beliefs is captured through fund flows. ${ }^{6}$ Therefore, if performance-to-fund-flow sensitivities (i.e., performanceflow sensitivities) are more volatile with moral hazard than without, performance must contain more information because investors are reacting more strongly. Define a fund's relative net flow as,

$$
\Delta K\left(\mathbb{1}_{S_{1}}\right) \equiv \frac{K_{2}\left(\mathbb{1}_{S_{1}}\right)-K_{1}}{K_{1}}
$$

The expression in Eq. (21) immediately extends itself to the following lemma.

Lemma 3. If $\theta^{*}<1$, a fund that succeeds (fails) at $t=1$ experiences a positive (negative) net fund flow at $t=2$.

Lemma 3 is natural - as long as there is a fraction of funds that are truly active, fund flows are positively related to realized performance. The following corollary characterizes performance-flow sensitivities.

Corollary 1.1. Performance-flow sensitivities, $\Delta K(1)-\Delta K(0)$, are

(i) decreasing in $F_{P}$,

(ii) increasing in $c$,

\footnotetext{
${ }^{6}$ For empirical work regarding the so-called "fund-flow anomaly," see Ippolito (1992), Chevalier and Ellison (1997), Sirri and Tufano (1998).
} 
(iii) increasing in $\eta$.

The comparative statics with respect to $F_{E}$ and $\alpha$ are equivocal.

A quick comparison of Proposition 1 to Corollary 1.1 provides straightforward intuition: funds' performance-flow sensitivities increase when the fraction of faux-active funds increases. ${ }^{7}$ In fact, the result suggests that the performance-flow sensitivities in the Berk and Green (2004) model in which there is no moral hazard are dampened relative to a setting in which moral hazard exists. The intuition for the result is that returns provide a signal of both skill and effort. Because fund flows are the channel that communicates investors' beliefs, Corollary 1.1 implies that a stronger signal-to-noise ratio is associated with greater fund-flow volatility. Therefore, greater moral hazard yields an unanticipated benefit to investors. While investors initially expect lower gross returns with moral hazard versus without, realized performance is more informative and investors are able to identify skilled managers more quickly. Fig. 2 diagrams a simple example showing investors' belief evolution with moral hazard and without.

\subsection{Empirical implications}

Our results on moral hazard and fund-flow sensitivities have several empirical implications. However, before discussing these implications, it is important to note that all of our equilibrium predictions need to be considered in the context of a partial-equilibrium model, recognizing that the contract is exogenously imposed. Our assumed contract is common between mutual funds and their investors. However, contracts between mutual funds and their managers, who likely control effort choices, may differ substantially. While Section 3 shows the robustness of our main results in an alternative setting featuring performance-based fees (i.e., the simplified contracting environment is not driving our results), empiricists should take care in applying our implications to environments different from our model's assumptions.

With those caveats, Proposition 1 provides several empirical implications. First, our result that falling passive fees lead to increased moral hazard is consistent with general trends in asset

\footnotetext{
${ }^{7}$ Huang et al. (2007) characterize funds' performance-flow sensitivities in a framework in which investors have heterogeneous participation costs. In our setup, performance-flow sensitivities are related to the equilibrium level of faux-active funds and not to investor characteristics.
} 
management over recent decades. While passive fees have fallen (French, 2008), evidence suggests that moral hazard may have become more severe. In particular, decreases in Active Share, which attempts to measure closet indexing, have corresponded with reductions in passive fees. However, another possible interpretation of decreasing Active Share is that funds have increasingly reached their optimal scales, and as a result, are indexing fund inflows. Thus, while the proportion of funds' being indexed increases, it is not necessarily associated with increased moral hazard. Second, the positive relation between $\eta$ and $\theta^{*}$ suggests that more severe moral hazard may manifest in niche market segments, or industries with high competition and highly crowded trades.

Corollary 1.1 also provides several empirical implications. Because moral hazard improves the information content in realized returns, higher moral hazard will be associated with higher fundflow sensitivities. Empirically, our result is likely found in situations where learning about funds' types is particularly sharp or consequential (e.g., at the beginning or end of funds' lives). Therefore, we predict: (i) funds' performance-flow sensitivities early in their lives are stronger when moral hazard is more prevalent, and (ii) bad funds should go out of business more quickly when moral hazard is more prevalent.

\section{Performance-Based Fees}

In this extension, we analyze how performance-based fees interact with moral hazard. Although performance-based fees (i.e., fulcrum fees) are rare in practice, it is natural to think that highpowered managerial incentives would partially mitigate the moral hazard conflict. ${ }^{8}$ Thus, one might expect performance-based fees to mitigate moral hazard. We show that this is not always the case.

\footnotetext{
${ }^{8}$ The 1970 Amendment to the Investment Advisers Act of 1940 introduced a performance-based fee option for mutual funds. The performance-based fee, however, is only admissible if it is a "fulcrum" fee, i.e., the performance component must be symmetric around a predetermined benchmark. The 1970 Amendment implicitly prohibits the standard asymmetric performance-based fees used in other managed products, e.g., the "2-and-20" schedule used by many hedge funds. In related research, Das and Sundaram (2002) compare fulcrum and incentive fees, showing that fee structures influence managers' incentives to take on risk in their portfolios. We take fees as given and fixed over time, and rather than focusing on welfare implications, focus on their effects on managers' incentives to exert costly effort.
} 
In addition to charging a management fee of $F_{E}+F_{P}$, a fund now retains a fraction of excess returns,

$$
\lambda>0 .
$$

Lemma 4. A fund's capital allocations in periods 1 and 2 are given by

$$
\begin{aligned}
K_{1}^{\lambda} & =\max \left\{\frac{\alpha(1-\lambda) \operatorname{Pr}\left(S_{1}^{\star}\right)-F_{E}}{\eta F_{E}}, 0\right\}, \\
K_{2}^{\lambda}\left(\mathbb{1}_{S_{1}}\right) & =\max \left\{\frac{\alpha(1-\lambda) \operatorname{Pr}\left(S_{2}^{\star} \mid \mathbb{1}_{S_{1}}\right)-F_{E}}{\eta F_{E}}, 0\right\} .
\end{aligned}
$$

The comparative statics of $K_{1}^{\lambda}$ and $K_{2}^{\lambda}\left(\mathbb{1}_{S_{1}}\right)$ with respect to $\lambda$ are natural: a fund's AUM is diminishing as the fund retains a larger portion of excess returns.

Funds endogenously separate as truly active funds or as faux-active funds depending on those actions' payoffs. Similar to the base model, there exists a unique threshold for which a fund with skill level above the threshold chooses to be a truly active fund and a fund with a skill level below it chooses to be faux-active.

Lemma 5. In a setup in which funds charge both a management fee and a performance-based fee, there exists a unique equilibrium in which a fund chooses whether or not to incur effort cost $c$ according to a threshold,

$$
\theta^{\lambda} \in(0,1]
$$

A fund with type $\theta<\theta^{\lambda}$ chooses to not incur effort cost $c$ and is a faux-active fund $(A)$. A fund with type $\theta \geq \theta^{\lambda}$ chooses to incur effort cost $c$ and is a truly active fund $(A)$.

So far, the results of a setup with a performance-based fee are redolent of a setup with only a fixed management fee. However, as Lemma 6 demonstrates, the performance-based fee's level has vacillating implications on the fraction of faux-active funds.

Lemma 6. The comparative static of $\theta^{\lambda}$ is first decreasing and then increasing in $\lambda$.

Introducing a performance-based fee has two opposite effects on funds' incentives. First, a performance-based fee reduces the expected abnormal returns which are passed on to investors, lowering funds' AUM. As funds' profits depend on AUM directly, reducing AUM is costly and provides less incentive for exerting effort, encouraging more shirking. Second, funds internalize a portion of their effort decision and directly benefit from $\alpha$. Keeping a portion of excess returns is 
very beneficial for highly skilled funds, as their true type is higher than investors' beliefs. Keeping a portion of excess returns is also beneficial for all truly active funds relative to faux-active funds. Only truly active funds have a positive probability of earning $\alpha$, a portion of which is retained via the performance fee.

When $\lambda$ is zero, increasing it marginally has a positive impact on managers' incentive to exert effort, reducing the moral hazard conflict. From a performance-based fee of zero, AUM is only perturbed slightly. However, the benefit of the performance-based fee is only felt by truly active funds, making it more costly to be a faux-active fund. As a result, more funds exert effort, and at least initially, performance-based fees help to mitigate the moral hazard problem. However, as $\lambda$ becomes larger, the funds' own profits are hurt substantially by reduced AUM. With more substantial performance fees, the negative impact on AUM outweighs the benefit of retaining profits internally. Decreased AUM impacts the marginal fund negatively and, as a result, shirking increases. In the limit, even the most highly skilled funds are affected and $\lambda=1$ halts managerial effort altogether. This result highlights that excessive performance-based fees can actually exacerbate moral hazard in asset management.

\section{Detecting moral hazard}

In our base model, investors use binary returns to infer a manager's type and effort. In reality, investors observe continuous returns and can also use holdings data to make inferences. In fact, managers' choices of holdings influence the dispersion of returns. For example, a shirking manager who invests only in the benchmark will provide a return with zero tracking error. When abnormal returns from active strategies are noisy, this manager would almost certainly be revealed as a shirker. In this section, we extend our base model to incorporate noisy returns and thereby give investors richer signals of managers' types and efforts.

In reality, investors can observe holdings data in addition to returns and tracking error. For example, the Cremers and Petajisto (2009) Active Share measure uses a distance measure between a fund's benchmark and its holdings to determine what fraction of the portfolio is "active." In our model, providing investors with holdings data would not allow for better identification of funds' activities. Instead, it would prevent shirking managers from solely investing in the benchmark, but it would not prevent those managers from randomly selecting stocks such that their portfolios 
appear active. In equilibrium, shirking managers would have no choice but to emulate the patterns of active managers' holdings (e.g., number of stocks, size of positions). Accordingly, rather than allowing investors to observe two separate signals (binary returns and observed holdings), we allow returns to be noisy, and endogenize the first and second moments of managers' return distributions. This setup is similar to allowing the investors to observe tracking error in addition to returns.

By allowing shirking managers to add noise to their returns, we model the ability to engage in signal-jamming, e.g., taking uninformed bets to generate a false sense of truly active management. While measures based on holdings, such as Active Share and tracking error, have had predictive power in the past, it is not obvious that the strategies of shirking managers will not adapt. We show numerically that signal-jamming should be expected as an equilibrium outcome.

The main assumptions from the base model are maintained: each fund manager's skill is individually and identically distributed according to the distribution $g(\tilde{\theta})$ (uniform in the numerical methods), funds that engage in truly active management pay a fixed effort cost $c>0$, and fees contain both a passive management component $F_{P}$ and an active management component $F_{E}$. In this extension, however, a truly active fund's excess returns $\tilde{\alpha}_{j, t}$ are distributed normally,

$$
\tilde{\alpha}_{j, t} \sim N\left(\frac{\alpha \theta}{1+\eta K_{t}}, \sigma_{A}^{2}\right)
$$

where $\sigma_{A}^{2}$ is exogenous. Faux-active funds are aware that truly active funds will realize the market return with probability zero, so reporting the market return would almost surely identify a fauxactive fund as a shirker. Therefore, we allow faux-active funds' excess returns, $\epsilon_{j, t}$, which are zero in expectation, to be noisy,

$$
\epsilon_{j, t} \sim N\left(0, \sigma_{A}^{2}\right)
$$

where $\sigma_{A}^{2}$ is endogenously chosen by the faux-active funds. Faux-active funds' variance choices are achieved by making uninformed bets via over- and under-weighting many of the benchmark's components or purchasing out-of-benchmark stocks. We return to the choice of $\sigma_{\mathscr{A}}^{2}$ shortly.

The setup implies that the distribution of returns for a fund that pays $c$ first-order-stochastically dominates the return distribution if the fund did not exert effort. The setup also better captures the underlying portfolio problem: a highly skilled manager ( $\theta$ near 1$)$ will identify many profitable trades and expects to earn abnormal returns. A marginally skilled manager $\left(\theta\right.$ near $\left.\theta^{*}\right)$ will be able to identify some profitable trades but will also make some mistakes. Nonetheless, the marginally 
skilled manager expects more profitable trades than unprofitable ones. This feature is captured by parameterizing the mean of a truly active manager's distribution by his type. Furthermore, for consistency with the base model, the mean is scaled by $\frac{1}{1+\eta K_{t}}$ to reflect decreasing-returns-to-scale.

As in the base model, funds choose to be truly active if the benefit to doing so is positive. Similar to Eq. (18), the benefit to being truly active depends on a fund's type and exogenous parameters, but now expected separation in second-period capital matters:

$$
\begin{aligned}
\tilde{\Delta}(\theta) & \equiv \Pi_{j}(A \mid \theta)-\Pi_{j}(A \mid \theta), \\
& =\frac{\theta\left(F_{E}+F_{P}\right)}{1+\eta K_{1}}\left(E\left[K_{2}\left(\theta^{* *}, \tilde{\alpha}_{j, t}\right)\right]-E\left[K_{2}\left(\theta^{* *}, \tilde{\epsilon}_{j, t}\right)\right]\right)-c,
\end{aligned}
$$

where $\theta^{* *}$ denotes the marginal fund in equilibrium, which will satisfy $\tilde{\Delta}\left(\theta^{* *}\right)=0$.

The second equation that determines the equilibrium is faux-active funds' choice of $\sigma_{\mathcal{A}}^{2}$. For simplicity, we assume all faux-active funds choose to add the same level of noise to their returns, which is the level that maximizes expected profits to the faux-active funds:

$$
\max _{\sigma_{\not}^{2}}\left(F_{E}+F_{P}\right)\left(K_{1}\left(\theta^{* *}\right)+E\left[K_{2}\left(\theta^{* *}, \tilde{\epsilon}_{j, t}\right)\right]\right) .
$$

Consistent with rational expectations, $\theta^{* *}$ and $\sigma_{A}^{2 *}$ are chosen simultaneously by funds, and both are known to investors when making their capital allocation decision.

The setup allows a skilled manager to underperform; even a highly skilled manager has positive probability on losing money. Conversely, the setup allows a faux-active fund to get lucky and achieve positive abnormal returns. The additional richness of normally distributed returns comes at the cost of analytic tractability. Consequently, we use numerical methods to solve the model incorporating normally distributed profits. Numerical analysis of the model yields similar insights as in Proposition 1.

Remark 1. In a setup with normally distributed excess returns, there exists an equilibrium in which a fund chooses whether or not to incur effort cost c according to a threshold,

$$
\theta^{* *} \in(0,1]
$$

A fund with type $\theta<\theta^{* *}$ chooses to not incur effort cost $c$ and is a faux-active fund $(A)$. A fund with type $\theta \geq \theta^{* *}$ chooses to incur effort cost $c$ and is a truly active fund (A). The threshold's comparative statics match those in Proposition 1. Furthermore, the threshold is increasing in $\sigma_{A}^{2}$. 
Remark 1 reveals that $\theta^{* *}$ increases with $\sigma_{A}^{2}$. The finding is intuitive; the incentive to shirk increases as realized performance becomes a noisier signal of both managerial skill and effort choice.

Remark 2. In the equilibrium given by $\theta^{* *}$, a faux-active fund chooses a finite and strictly positive variance $\sigma_{\mathscr{A}}^{2 *}$. The level of $\sigma_{\mathscr{A}}^{2 *}$ is positively correlated with $\theta^{* *}$.

Remark 2 implies that a faux-active fund necessarily deviates from its benchmark with uninformed bets. The extent of this "signal-jamming" behavior is positively related to the severity of the moral hazard conflict, i.e., strategic variance and shirking are complements. As more funds forgo exerting effort, the expected performance gap between truly active funds and faux-active funds increases. The larger gap leads faux-active funds to increase variance, directing more probabilistic weight to the expected performance outcomes of truly active funds. ${ }^{9}$

Remark 2 also suggests that holdings-based measures of moral hazard should account for strategic, uninformed deviations from index weightings. Even in a world with risk aversion, we expect funds will add strategic variance, as not adding variance would almost surely identify the fund as faux-active. Therefore, as investors attempt to use holdings or tracking error to identify fund skill and effort (or a lack thereof), we expect that shirking managers will counteract these identification methods. In the future, holdings and tracking error may be less effective for identifying skilled managers as shirking managers adapt to broad dissemination of this information.

\section{Conclusion}

We analyze asset managers' effort incentives, showing that reducing AUM profitability or the ability of highly skilled, active managers to separate via performance leads to increased moral hazard. In particular, our analysis links falling fees associated with the growth of passive investing to active managers' incentives, showing that lower fees lead to less managerial effort (e.g., a reduction in information production). While the widespread adoption of index investing has been viewed as a boon for investors, recent research associates passive investing with reduced market efficiency (see,

\footnotetext{
${ }^{9}$ Heinkel and Stoughton (1994) consider a similar problem and emphasize that the variance has an internal maximum. In our context, too much variance results in very high returns being more attributed to faux-active funds than to truly active funds.
} 
e.g., Ben-David, Franzoni, and Moussawi, 2014; Israeli, Lee, and Sridharan, 2017; Da and Shive, 2016). Faux-active funds may be exacerbating such effects.

If passive management fees continue to fall, market efficiency may be further harmed as moral hazard becomes more severe. The negative externality may manifest itself through increased closet indexing, i.e., more passive management, or through less effective active management, i.e., less capital employed by truly active managers. As such, the moral hazard conflict likely accentuates passive investing's negative impact on market efficiency rather than remedying it. Mitigating the negative spillover effects due to reduced effort is not trivial. Popular holdings-based measures may not be effective as funds can engage in signal-jamming to appear truly active. 


\section{Appendix A}

\section{Proof of Lemma 1:}

The expressions in Eqs. (8) and (9) are rewritten as,

$$
\begin{aligned}
& F_{E}=\alpha \operatorname{Pr}\left(S_{1} \mid K_{1}, \eta\right), \\
& F_{E}=\alpha \operatorname{Pr}\left(S_{2} \mid K_{2}, \eta, \mathbb{1}_{S_{1}}\right) .
\end{aligned}
$$

The expressions are expanded to incorporate Eq. (5) while using Eqs. (10) and (11) to simplify notation,

$$
\begin{aligned}
& F_{E}=\frac{\alpha \operatorname{Pr}\left(S_{1}^{\star}\right)}{1+\eta K_{1, t}}, \\
& F_{E}=\frac{\alpha \operatorname{Pr}\left(S_{2}^{\star} \mid \mathbb{1}_{S_{1}}\right)}{1+\eta K_{2, t}} .
\end{aligned}
$$

The non-negative solutions to the preceding expressions are given by,

$$
\begin{aligned}
K_{1} & =\max \left\{\frac{\alpha \operatorname{Pr}\left(S_{1}^{\star}\right)-F_{E}}{\eta F_{E}}, 0\right\}, \\
K_{2}\left(\mathbb{1}_{S_{1}}\right) & =\max \left\{\frac{\alpha \operatorname{Pr}\left(S_{2}^{\star} \mid \mathbb{1}_{S_{1}}\right)-F_{E}}{\eta F_{E}}, 0\right\} .
\end{aligned}
$$

\section{Proof of Lemma 2:}

The profit functions in Eq. (16) are rewritten using Eqs. (14) and (15),

$$
\Pi_{j}\left(\mathrm{a}_{j}, F_{E}\right)= \begin{cases}\left(F_{E}+F_{P}\right)\left(\max \left\{\frac{\alpha \operatorname{Pr}\left(S_{1}^{\star}\right)-F_{E}}{\eta F_{E}}, 0\right\}+\max \left\{\frac{\alpha \operatorname{Pr}\left(S_{2}^{\star} \mid 0\right)-F_{E}}{\eta F_{E}}, 0\right\}\right) & \text { if a }=A, \\ \left(F_{E}+F_{P}\right)\left(\max \left\{\frac{\alpha \operatorname{Pr}\left(S_{1}^{\star}\right)-F_{E}}{\eta F_{E}}, 0\right\}+\max \left\{\frac{\alpha \operatorname{Pr}\left(S_{2}^{\star} \mid \mathbb{1}_{S_{1}}\right)-F_{E}}{\eta F_{E}}, 0\right\}\right)-c & \text { if a }=A .\end{cases}
$$

The profit functions in Eq. (A7) yield an explicit form of $\Delta(\theta)$. The function $\Delta(\theta)$ defined in Eq. (18), is explicitly given by,

$$
\Delta(\theta)=\frac{\theta\left(F_{E}+F_{P}\right)}{1+\eta K_{1}}\left(\max \left\{\frac{\alpha \operatorname{Pr}\left(S_{2}^{\star} \mid 1\right)-F_{E}}{\eta F_{E}}, 0\right\}-\max \left\{\frac{\alpha \operatorname{Pr}\left(S_{2}^{\star} \mid 0\right)-F_{E}}{\eta F_{E}}, 0\right\}\right)-c .
$$

$\Delta(\theta)$ is clearly increasing in $\theta$ because $\operatorname{Pr}\left(S_{2}^{\star} \mid 1\right)$ and $\operatorname{Pr}\left(S_{2}^{\star} \mid 0\right)$ do not depend on $\theta$ and an individual fund's decision does not impact $\theta^{*}$. Furthermore, $\Delta(0)<0$ for $c>0$ and $\operatorname{Max}(\Delta(\theta))$ is achieved at $\theta=1$. By the intermediate value theorem, if there is an internal solution it must be that $\theta^{*} \in(0,1]$. 
Note that if an internal value of $\theta$ satisfies $\Delta(\theta)=0$, the following equality implicitly defines $\theta^{*}$,

$$
\theta^{*}=\frac{c\left(1+\eta \max \left\{\frac{\alpha \operatorname{Pr}\left(S_{1}^{\star}\right)-F_{E}}{\eta F_{E}}, 0\right\}\right)}{\left(F_{E}+F_{P}\right)\left(\max \left\{\frac{\alpha \operatorname{Pr}\left(S_{2}^{\star} \mid 1\right)-F_{E}}{\eta F_{E}}, 0\right\}-\max \left\{\frac{\alpha \operatorname{Pr}\left(S_{2}^{\star} \mid 0\right)-F_{E}}{\eta F_{E}}, 0\right\}\right)} .
$$

Focusing on the non-trivial case in which capital at $t=1$ is positive, the expression simplifies to,

$$
\theta^{*}=\frac{c \eta \alpha \operatorname{Pr}\left(S_{1}^{\star}\right)}{\left(F_{E}+F_{P}\right)\left(\alpha \operatorname{Pr}\left(S_{2}^{\star} \mid 1\right)-F_{E}-\max \left\{\alpha \operatorname{Pr}\left(S_{2}^{\star} \mid 0\right)-F_{E}, 0\right\}\right)} .
$$

\section{Proof of Proposition 1:}

Define

$$
\Psi(\hat{\theta}) \equiv \hat{\theta}-\frac{c \eta \alpha \operatorname{Pr}\left(S_{1}^{\star} \mid \hat{\theta}\right)}{\left(F_{E}+F_{P}\right)\left(\alpha \operatorname{Pr}\left(S_{2}^{\star} \mid 1, \hat{\theta}\right)-F_{E}-\max \left\{\alpha \operatorname{Pr}\left(S_{2}^{\star} \mid 0, \hat{\theta}\right)-F_{E}, 0\right\}\right)} .
$$

Note that $\Psi\left(\theta^{*}\right)=0$. The function $\Psi(\hat{\theta})$ can be utilized with the implicit function theorem to characterize $\theta^{*}$,

$$
\frac{\partial \theta^{*}}{\partial \omega}=-\left.\frac{\partial \Psi / \partial \omega}{\partial \Psi / \partial \hat{\theta}}\right|_{\hat{\theta}=\theta^{*}},
$$

for $\omega \in\left\{c, F_{P}, \alpha, \eta, F_{E}\right\}$. In the comparative statics studied hereafter, there are two cases to consider:

(i) $\max \left\{\alpha \operatorname{Pr}\left(S_{2}^{\star} \mid 0, \hat{\theta}\right)-F_{E}, 0\right\}=\alpha \operatorname{Pr}\left(S_{2}^{\star} \mid 0, \hat{\theta}\right)-F_{E}$ and,

(ii) $\max \left\{\alpha \operatorname{Pr}\left(S_{2}^{\star} \mid 0, \hat{\theta}\right)-F_{E}, 0\right\}=0$.

Respectively, define $\Psi(\hat{\theta})$ in each of these two cases as,

$$
\begin{aligned}
& \Psi^{Q^{\prime}}(\hat{\theta}) \equiv \hat{\theta}-\frac{c \eta \operatorname{Pr}\left(S_{1}^{\star} \mid \hat{\theta}\right)}{\left(F_{E}+F_{P}\right)\left(\operatorname{Pr}\left(S_{2}^{\star} \mid 1, \hat{\theta}\right)-\operatorname{Pr}\left(S_{2}^{\star} \mid 0, \hat{\theta}\right)\right)} \\
& \Psi^{0}(\hat{\theta}) \equiv \hat{\theta}-\frac{c \eta \alpha \operatorname{Pr}\left(S_{1}^{\star} \mid \hat{\theta}\right)}{\left(F_{E}+F_{P}\right)\left(\alpha \operatorname{Pr}\left(S_{2}^{\star} \mid 1, \hat{\theta}\right)-F_{E}\right)} .
\end{aligned}
$$

Before signing the partial derivatives, we derive explicitly the probabilities of success and their derivatives. Rearranging Eqs. (12) and (13) gives

$$
\begin{aligned}
\operatorname{Pr}\left(S_{1}^{\star}\right) & \equiv \operatorname{Pr}\left(S_{1} \mid K_{1}, \eta\right)\left(1+\eta K_{1}\right), \\
\operatorname{Pr}\left(S_{2}^{\star} \mid \mathbb{1}_{S_{1}}\right) & \equiv \operatorname{Pr}\left(S_{2} \mid K_{2}, \eta, \mathbb{1}_{S_{1}}\right)\left(1+\eta K_{2}\right) .
\end{aligned}
$$


The explicit forms of $\operatorname{Pr}\left(S_{1}^{\star}\right), \operatorname{Pr}\left(S_{2}^{\star} \mid 1\right)$, and $\operatorname{Pr}\left(S_{2}^{\star} \mid 0\right)$ are now derived, starting with $\operatorname{Pr}\left(S_{1}^{\star}\right)$,

$$
\begin{aligned}
\operatorname{Pr}\left(S_{1}^{\star}\right) & =\operatorname{Pr}\left(S_{1}^{\star} \mid A\right) \operatorname{Pr}(A)+\operatorname{Pr}\left(S_{1}^{\star} \mid A\right) \operatorname{Pr}(A) \\
& =\operatorname{Pr}\left(S_{1}^{\star} \mid A\right) \operatorname{Pr}(A) \\
& =\frac{\int_{\theta^{*}}^{1} \theta g(\theta) \mathrm{d} \theta}{\int_{\theta^{*}}^{1} g(\theta) \mathrm{d} \theta}\left(\int_{\theta^{*}}^{1} g(\theta) \mathrm{d} \theta\right) \\
& =\int_{\theta^{*}}^{1} \theta g(\theta) \mathrm{d} \theta .
\end{aligned}
$$

Now, consider $\operatorname{Pr}\left(S_{2}^{\star} \mid 1\right)$,

$$
\begin{aligned}
\operatorname{Pr}\left(S_{2}^{\star} \mid 1\right) & =\operatorname{Pr}\left(S_{2}^{\star} \mid A, 1\right) \operatorname{Pr}(A \mid 1)+\operatorname{Pr}\left(S_{2}^{\star} \mid A, 1\right) \operatorname{Pr}(A \mid 1) \\
& =\frac{\operatorname{Pr}\left(S_{2}^{\star} \cap 1 \mid A\right)}{\operatorname{Pr}(1 \mid A)} \operatorname{Pr}(A \mid 1) \\
& =\frac{\int_{\theta^{*}}^{1} \frac{\theta^{2}}{1+\eta K_{1}} g(\theta) \mathrm{d} \theta}{\int_{\theta^{*}}^{1} \frac{\theta}{1+\eta K_{1}} g(\theta) \mathrm{d} \theta} \\
& =\frac{\int_{\theta^{*}}^{1} \theta^{2} g(\theta) \mathrm{d} \theta}{\int_{\theta^{*}}^{1} \theta g(\theta) \mathrm{d} \theta} .
\end{aligned}
$$

Now, consider $\operatorname{Pr}\left(S_{2}^{\star} \mid 0\right)$,

$$
\begin{aligned}
\operatorname{Pr}\left(S_{2}^{\star} \mid 0\right) & =\operatorname{Pr}\left(S_{2}^{\star} \mid A, 0\right) \operatorname{Pr}(A \mid 0)+\operatorname{Pr}\left(S_{2}^{\star} \mid A, 0\right) \operatorname{Pr}(A \mid 0) \\
& =\frac{\operatorname{Pr}\left(S_{2}^{\star} \cap 0 \mid A\right)}{\operatorname{Pr}(0 \mid A)} \frac{\operatorname{Pr}(0 \mid A) \operatorname{Pr}(A)}{\operatorname{Pr}(0 \mid A) \operatorname{Pr}(A)+\operatorname{Pr}(0 \mid A) \operatorname{Pr}(A)} \\
& =\left(\frac{\frac{\int_{\theta^{*}}^{1} \theta\left(1-\frac{\theta}{1+\eta K_{1}}\right) g(\theta) \mathrm{d} \theta}{1-G\left(\theta^{*}\right)}}{\frac{\left(1-G\left(\theta^{*}\right)\right) \frac{\int_{\theta^{*}}^{1}\left(1-\frac{\theta}{1+\eta K_{1}}\right) g(\theta) \mathrm{d} \theta}{\left(1-G\left(\theta^{*}\right)\right)}}{\left.1-\frac{\theta}{1+\eta K_{1}}\right) g(\theta) \mathrm{d} \theta}}\right)\left(\frac{\left(1-G\left(\theta^{*}\right)\right.}{\left(1-G\left(\theta^{*}\right)\right) \frac{\int_{\theta^{*}}^{1}\left(1-\frac{\theta}{1+\eta K_{1}}\right) g(\theta) \mathrm{d} \theta}{\left(1-G\left(\theta^{*}\right)\right)}+G\left(\theta^{*}\right)}\right) \\
& =\frac{\alpha \operatorname{Pr}\left(S_{1}^{\star}\right)^{2}-F_{E} \int_{\theta^{*}}^{1} \theta^{2} g(\theta) \mathrm{d} \theta}{\operatorname{Pr}\left(S_{1}^{\star}\right)\left(\alpha-F_{E}\right)} .
\end{aligned}
$$

Note that $\operatorname{Pr}\left(S_{1}^{\star}\right)$ is decreasing in $\theta^{*}, \operatorname{Pr}\left(S_{2}^{\star} \mid 1\right)$ is increasing in $\theta^{*}$, and $\operatorname{Pr}\left(S_{2}^{\star} \mid 0\right)$ is decreasing in $\theta^{*}$,

$$
\begin{aligned}
\frac{\partial \operatorname{Pr}\left(S_{1}^{\star}\right)}{\partial \theta^{*}} & =-\theta^{*} g\left(\theta^{*}\right) \\
& \leq 0 . \\
\frac{\partial \operatorname{Pr}\left(S_{2}^{\star} \mid 1\right)}{\partial \theta^{*}} & =\frac{\theta^{*} g\left(\theta^{*}\right)}{\int_{\theta^{*}}^{1} \theta g(\theta) \mathrm{d} \theta}\left(\operatorname{Pr}\left(S_{2}^{\star} \mid 1\right)-\theta^{*}\right),
\end{aligned}
$$


which is positive because $\operatorname{Pr}\left(S_{2}^{\star} \mid 1\right)=E[\theta \mid 1, A] \geq \theta^{*}$,

$$
\begin{aligned}
& \geq 0 . \\
\frac{\partial \operatorname{Pr}\left(S_{2}^{\star} \mid 0\right)}{\partial \theta^{*}} & =\frac{2 \alpha \operatorname{Pr}\left(S_{1}^{\star}\right) \frac{\partial \operatorname{Pr}\left(S_{1}^{\star}\right)}{\partial \theta^{*}}+F_{E} \theta^{* 2} g\left(\theta^{*}\right)}{\operatorname{Pr}\left(S_{1}^{\star}\right)\left(\alpha-F_{E}\right)}-\frac{\alpha \operatorname{Pr}\left(S_{1}^{\star}\right)^{2}-F_{E} \int_{\theta^{*}}^{1} \theta^{2} g(\theta) \mathrm{d} \theta}{\operatorname{Pr}\left(S_{1}^{\star}\right)^{2}\left(\alpha-F_{E}\right)} \frac{\partial \operatorname{Pr}\left(S_{1}^{\star}\right)}{\partial \theta^{*}} \\
& =\frac{\partial \operatorname{Pr}\left(S_{1}^{\star}\right)}{\partial \theta^{*}}\left(\frac{\alpha \operatorname{Pr}\left(S_{1}^{\star}\right)-F_{E} \theta^{*}}{\operatorname{Pr}\left(S_{1}^{\star}\right)\left(\alpha-F_{E}\right)}+\frac{F_{E} \int_{\theta^{*}}^{1} \theta^{2} g(\theta) \mathrm{d} \theta}{\operatorname{Pr}\left(S_{1}^{\star}\right)^{2}\left(\alpha-F_{E}\right)}\right),
\end{aligned}
$$

which is negative because $\frac{\partial \operatorname{Pr}\left(S_{1}^{\star}\right)}{\partial \theta^{*}} \leq 0$ and $\alpha \operatorname{Pr}\left(S_{1}^{\star}\right)-F_{E} \geq 0$,

$$
\leq 0
$$

Furthermore, note that,

$$
\begin{aligned}
\frac{\partial \operatorname{Pr}\left(S_{2}^{\star} \mid 0\right)}{\partial \alpha} & =\frac{\operatorname{Pr}\left(S_{1}^{\star}\right)^{2}}{\operatorname{Pr}\left(S_{1}^{\star}\right)\left(\alpha-F_{E}\right)}-\frac{\alpha \operatorname{Pr}\left(S_{1}^{\star}\right)^{2}-F_{E} \int_{\theta^{*}}^{1} \theta^{2} g(\theta) \mathrm{d} \theta}{\operatorname{Pr}\left(S_{1}^{\star}\right)\left(\alpha-F_{E}\right)^{2}} \\
& =\frac{-\operatorname{Pr}\left(S_{1}^{\star}\right)^{2} F_{E}}{\operatorname{Pr}\left(S_{1}^{\star}\right)\left(\alpha-F_{E}\right)^{2}}+\frac{F_{E} \int_{\theta^{*}}^{1} \theta^{2} g(\theta) \mathrm{d} \theta}{\operatorname{Pr}\left(S_{1}^{\star}\right)\left(\alpha-F_{E}\right)^{2}} \\
& \geq 0,
\end{aligned}
$$

because $\int \theta^{2} g(\theta)-\left(\int \theta g(\theta)\right)^{2}$ is positive. ${ }^{10}$ Finally, note that,

$$
\begin{aligned}
\frac{\partial \operatorname{Pr}\left(S_{2}^{\star} \mid 0\right)}{\partial F_{E}} & =\frac{-\int_{\theta^{*}}^{1} \theta^{2} g(\theta) \mathrm{d} \theta}{\operatorname{Pr}\left(S_{1}^{\star}\right)\left(\alpha-F_{E}\right)}+\frac{\alpha \operatorname{Pr}\left(S_{1}^{\star}\right)^{2}-F_{E} \int_{\theta^{*}}^{1} \theta^{2} g(\theta) \mathrm{d} \theta}{\operatorname{Pr}\left(S_{1}^{\star}\right)\left(\alpha-F_{E}\right)^{2}} \\
& =\frac{-\alpha \int_{\theta^{*}}^{1} \theta^{2} g(\theta) \mathrm{d} \theta}{\operatorname{Pr}\left(S_{1}^{\star}\right)\left(\alpha-F_{E}\right)^{2}}+\frac{\alpha \operatorname{Pr}\left(S_{1}^{\star}\right)^{2}}{\operatorname{Pr}\left(S_{1}^{\star}\right)\left(\alpha-F_{E}\right)^{2}} \\
& \leq 0,
\end{aligned}
$$

because $\int \theta^{2} g(\theta)-\left(\int \theta g(\theta)\right)^{2}$ is positive.

Using the signs given by Eqs. (A29), (A31), (A34), (A37), and (A40), we sign the partial

\footnotetext{
${ }^{10}$ It is simple to construct a proof which shows that $\int \theta^{2} g(\theta)-\left(\int \theta g(\theta)\right)^{2}$ is positive by beginning with the formula for conditional variance, $\frac{\int \theta^{2} g(\theta)}{1-G\left(\theta^{*}\right)}-\left(\frac{\int \theta g(\theta)}{1-G\left(\theta^{*}\right)}\right)^{2}$, which is positive.
} 
derivatives, beginning with $\partial \Psi^{Q} / \partial \hat{\theta}$ and $\partial \Psi^{0} / \partial \hat{\theta}$,

$$
\begin{aligned}
\frac{\partial \Psi^{\phi}}{\partial \hat{\theta}} & =1-\frac{c \eta \frac{\partial \operatorname{Pr}\left(S_{1}^{\star} \mid \hat{\theta}\right)}{\partial \hat{\theta}}}{\left(F_{E}+F_{P}\right)\left(\operatorname{Pr}\left(S_{2}^{\star} \mid 1, \hat{\theta}\right)-\operatorname{Pr}\left(S_{2}^{\star} \mid 0, \hat{\theta}\right)\right)} \\
& +\frac{c \eta \operatorname{Pr}\left(S_{1}^{\star} \mid \hat{\theta}\right)\left(\frac{\partial \operatorname{Pr}\left(S_{2}^{\star} \mid 1, \hat{\theta}\right)}{\partial \hat{\theta}}-\frac{\partial \operatorname{Pr}\left(S_{2}^{\star} \mid 0, \hat{\theta}\right)}{\partial \hat{\theta}}\right)}{\left(F_{E}+F_{P}\right)\left(\operatorname{Pr}\left(S_{2}^{\star} \mid 1, \hat{\theta}\right)-\operatorname{Pr}\left(S_{2}^{\star} \mid 0, \hat{\theta}\right)\right)^{2}} \\
& \geq 0, \\
\frac{\partial \Psi^{0}}{\partial \hat{\theta}} & =1-\frac{c \eta \alpha \frac{\partial \operatorname{Pr}\left(S_{1}^{\star} \mid \hat{\theta}\right)}{\partial \hat{\theta}}}{\left(F_{E}+F_{P}\right)\left(\alpha \operatorname{Pr}\left(S_{2}^{\star} \mid 1, \hat{\theta}\right)-F_{E}\right)} \\
& +\frac{c \eta \alpha^{2} \operatorname{Pr}\left(S_{1}^{\star} \mid \hat{\theta}\right) \frac{\partial \operatorname{Pr}\left(S_{2}^{\star} \mid 1, \hat{\theta}\right)}{\partial \hat{\theta}}}{\left(F_{E}+F_{P}\right)\left(\alpha \operatorname{Pr}\left(S_{2}^{\star} \mid 1, \hat{\theta}\right)-F_{E}\right)^{2}} \\
& \geq 0 .
\end{aligned}
$$

Now, we consider $\partial \Psi^{\varphi} / \partial c$ and $\partial \Psi^{0} / \partial c$,

$$
\begin{aligned}
\frac{\partial \Psi^{\phi}}{\partial c} & =-\frac{\eta \operatorname{Pr}\left(S_{1}^{\star} \mid \hat{\theta}\right)}{\left(F_{E}+F_{P}\right)\left(\operatorname{Pr}\left(S_{2}^{\star} \mid 1, \hat{\theta}\right)-\operatorname{Pr}\left(S_{2}^{\star} \mid 0, \hat{\theta}\right)\right)} \\
& \leq 0, \\
\frac{\partial \Psi^{0}}{\partial c} & =-\frac{\eta \alpha \operatorname{Pr}\left(S_{1}^{\star} \mid \hat{\theta}\right)}{\left(F_{E}+F_{P}\right)\left(\alpha \operatorname{Pr}\left(S_{2}^{\star} \mid 1, \hat{\theta}\right)-F_{E}\right)} \\
& \leq 0 .
\end{aligned}
$$

Now, we consider $\partial \Psi^{\phi} / \partial F_{P}$ and $\partial \Psi^{0} / \partial F_{P}$,

$$
\begin{aligned}
\frac{\partial \Psi^{\phi}}{\partial F_{P}} & =\frac{c \eta \operatorname{Pr}\left(S_{1}^{\star} \mid \hat{\theta}\right)}{\left(F_{E}+F_{P}\right)^{2}\left(\operatorname{Pr}\left(S_{2}^{\star} \mid 1, \hat{\theta}\right)-\operatorname{Pr}\left(S_{2}^{\star} \mid 0, \hat{\theta}\right)\right)} \\
& \geq 0, \\
\frac{\partial \Psi^{0}}{\partial F_{P}} & =\frac{c \eta \alpha \operatorname{Pr}\left(S_{1}^{\star} \mid \hat{\theta}\right)}{\left(F_{E}+F_{P}\right)^{2}\left(\alpha \operatorname{Pr}\left(S_{2}^{\star} \mid 1, \hat{\theta}\right)-F_{E}\right)} \\
& \geq 0 .
\end{aligned}
$$


Now, we consider $\partial \Psi^{\phi} / \partial \eta$ and $\partial \Psi^{0} / \partial \eta$,

$$
\begin{aligned}
\frac{\partial \Psi^{\phi}}{\partial \eta} & =-\frac{c \operatorname{Pr}\left(S_{1}^{\star} \mid \hat{\theta}\right)}{\left(F_{E}+F_{P}\right)\left(\operatorname{Pr}\left(S_{2}^{\star} \mid 1, \hat{\theta}\right)-\operatorname{Pr}\left(S_{2}^{\star} \mid 0, \hat{\theta}\right)\right)} \\
& \leq 0, \\
\frac{\partial \Psi^{0}}{\partial \eta} & =-\frac{c \alpha \operatorname{Pr}\left(S_{1}^{\star} \mid \hat{\theta}\right)}{\left(F_{E}+F_{P}\right)\left(\alpha \operatorname{Pr}\left(S_{2}^{\star} \mid 1, \hat{\theta}\right)-F_{E}\right)} \\
& \leq 0 .
\end{aligned}
$$

Now, we consider $\partial \Psi^{\phi} / \partial \alpha$ and $\partial \Psi^{0} / \partial \alpha$. The sign on the derivative is equivocal,

$$
\begin{aligned}
\frac{\partial \Psi^{\phi}}{\partial \alpha} & =-\frac{c \eta \operatorname{Pr}\left(S_{1}^{\star} \mid \hat{\theta}\right)}{\left(F_{E}+F_{P}\right)\left(\operatorname{Pr}\left(S_{2}^{\star} \mid 1, \hat{\theta}\right)-\operatorname{Pr}\left(S_{2}^{\star} \mid 0, \hat{\theta}\right)\right)^{2}} \frac{\partial \operatorname{Pr}\left(S_{2}^{\star} \mid 0, \hat{\theta}\right)}{\partial \alpha} \\
& \leq 0, \\
\frac{\partial \Psi^{0}}{\partial \alpha} & =\frac{c \eta \alpha \operatorname{Pr}\left(S_{1}^{\star} \mid \hat{\theta}\right) \operatorname{Pr}\left(S_{2}^{\star} \mid 1, \hat{\theta}\right)}{\left(F_{E}+F_{P}\right)\left(\alpha \operatorname{Pr}\left(S_{2}^{\star} \mid 1, \hat{\theta}\right)-F_{E}\right)^{2}} \\
& \geq 0 .
\end{aligned}
$$

Now, we consider $\partial \Psi^{\theta} / \partial F_{E}$ and $\partial \Psi^{0} / \partial F_{E}$. The sign on the derivative is equivocal,

$$
\begin{aligned}
\frac{\partial \Psi^{\phi}}{\partial F_{E}} & =\frac{c \eta \operatorname{Pr}\left(S_{1}^{\star} \mid \hat{\theta}\right)}{\left(F_{E}+F_{P}\right)^{2}\left(\operatorname{Pr}\left(S_{2}^{\star} \mid 1, \hat{\theta}\right)-\operatorname{Pr}\left(S_{2}^{\star} \mid 0, \hat{\theta}\right)\right)} \\
& -\frac{c \eta \operatorname{Pr}\left(S_{1}^{\star} \mid \hat{\theta}\right)}{\left(F_{E}+F_{P}\right)\left(\operatorname{Pr}\left(S_{2}^{\star} \mid 1, \hat{\theta}\right)-\operatorname{Pr}\left(S_{2}^{\star} \mid 0, \hat{\theta}\right)\right)^{2}} \frac{\partial \operatorname{Pr}\left(S_{2}^{\star} \mid 0, \hat{\theta}\right)}{\partial F_{E}} \\
& \geq 0, \\
\frac{\partial \Psi^{0}}{\partial F_{E}} & =\frac{c \eta \alpha \operatorname{Pr}\left(S_{1}^{\star} \mid \hat{\theta}\right)}{\left(F_{E}+F_{P}\right)^{2}\left(\alpha \operatorname{Pr}\left(S_{2}^{\star} \mid 1, \hat{\theta}\right)-F_{E}\right)} \\
& -\frac{c \eta \alpha \operatorname{Pr}\left(S_{1}^{\star} \mid \hat{\theta}\right)}{\left(F_{E}+F_{P}\right)\left(\alpha \operatorname{Pr}\left(S_{2}^{\star} \mid 1, \hat{\theta}\right)-F_{E}\right)^{2}} \\
& \gtreqless 0 .
\end{aligned}
$$

The sign is weakly positive if and only if,

$$
F_{E} \leq \frac{\alpha \operatorname{Pr}\left(S_{2}^{\star} \mid 1, \hat{\theta}\right)-F_{P}}{2} .
$$


The following summarizes the comparative statics,

$$
\begin{aligned}
\frac{\partial \theta^{*}}{\partial c} & =-\left.\frac{\partial \Psi / \partial c}{\partial \Psi / \partial \hat{\theta}}\right|_{\hat{\theta}=\theta^{*}} \\
& \geq 0 . \\
\frac{\partial \theta^{*}}{\partial F_{P}} & =-\left.\frac{\partial \Psi / \partial F_{P}}{\partial \Psi / \partial \hat{\theta}}\right|_{\hat{\theta}=\theta^{*}} \\
& \leq 0 . \\
\frac{\partial \theta^{*}}{\partial \eta} & =-\left.\frac{\partial \Psi / \partial \eta}{\partial \Psi / \partial \hat{\theta}}\right|_{\hat{\theta}=\theta^{*}} \\
& \geq 0 . \\
\frac{\partial \theta^{*}}{\partial \alpha} & =-\left.\frac{\partial \Psi / \partial \alpha}{\partial \Psi / \partial \hat{\theta}}\right|_{\hat{\theta}=\theta^{*}} \\
& \geqq 0 \text { the comparative static is equivocal. } \\
\frac{\partial \theta^{*}}{\partial F_{E}} & =-\left.\frac{\partial \Psi / \partial F_{E}}{\partial \Psi / \partial \hat{\theta}}\right|_{\hat{\theta}=\theta^{*}} \\
& \gtreqless 0 \text { the comparative static is equivocal. }
\end{aligned}
$$

\section{Proof of Lemma 3:}

An explicit form for $\Delta K\left(\mathbb{1}_{S_{1}}\right)$ is given by,

$$
\Delta K\left(\mathbb{1}_{S_{1}}\right)=\frac{\max \left\{\alpha \operatorname{Pr}\left(S_{2}^{\star} \mid \mathbb{1}_{S_{1}}\right)-F_{E}, 0\right\}}{\alpha \operatorname{Pr}\left(S_{1}^{\star}\right)-F_{E}}-1 .
$$

Now, consider that a fund succeeds. According to Eq. (A77), the fund's net fund flow is given by,

$$
\Delta K(1)=\frac{\alpha \operatorname{Pr}\left(S_{2}^{\star} \mid 1\right)-F_{E}}{\alpha \operatorname{Pr}\left(S_{1}^{\star}\right)-F_{E}}-1
$$

which is strictly positive because $\operatorname{Pr}\left(S_{2}^{\star} \mid 1\right)>\operatorname{Pr}\left(S_{1}^{\star}\right)$,

$$
>0
$$

A similar analysis demonstrates that $\Delta K(0)<0$.

Proof of Corollary 1.1: 
An explicit form for $\Delta K\left(\mathbb{1}_{S_{1}}\right)$ is given by,

$$
\Delta K\left(\mathbb{1}_{S_{1}}\right)=\frac{\max \left\{\alpha \operatorname{Pr}\left(S_{2}^{\star} \mid \mathbb{1}_{S_{1}}\right)-F_{E}, 0\right\}}{\alpha \operatorname{Pr}\left(S_{1}^{\star}\right)-F_{E}}-1 .
$$

For any parameter $\varphi \in\left\{c, F_{P}, \eta\right\}$ the comparative static is given by,

$$
\begin{aligned}
\frac{\partial \Delta K\left(\mathbb{1}_{S_{1}}\right)}{\partial \varphi} & =\frac{\partial}{\partial \varphi}\left(\frac{\alpha \operatorname{Pr}\left(S_{2}^{\star} \mid \mathbb{1}_{S_{1}}\right)-F_{E}}{\alpha \operatorname{Pr}\left(S_{1}^{\star}\right)-F_{E}}-1\right) \\
& =\frac{\alpha \frac{\partial \operatorname{Pr}\left(S_{2}^{\star} \mid \mathbb{1}_{S_{1}}\right)}{\partial \theta^{*}} \frac{\partial \theta^{*}}{\partial \varphi}}{\alpha \operatorname{Pr}\left(S_{1}^{\star}\right)-F_{E}}-\frac{\alpha\left(\alpha \operatorname{Pr}\left(S_{2}^{\star} \mid \mathbb{1}_{S_{1}}\right)-F_{E}\right)}{\left(\alpha \operatorname{Pr}\left(S_{1}^{\star}\right)-F_{E}\right)^{2}} \frac{\partial \operatorname{Pr}\left(S_{1}^{\star}\right)}{\partial \theta^{*}} \frac{\partial \theta^{*}}{\partial \varphi} \\
& =\alpha \frac{\partial \theta^{*}}{\partial \varphi}\left(\frac{\frac{\partial \operatorname{Pr}\left(S_{2}^{\star} \mid \mathbb{1}_{S_{1}}\right)}{\partial \theta^{*}}}{\alpha \operatorname{Pr}\left(S_{1}^{\star}\right)-F_{E}}-\frac{\alpha \operatorname{Pr}\left(S_{2}^{\star} \mid \mathbb{1}_{S_{1}}\right)-F_{E}}{\left(\alpha \operatorname{Pr}\left(S_{1}^{\star}\right)-F_{E}\right)^{2}} \frac{\partial \operatorname{Pr}\left(S_{1}^{\star}\right)}{\partial \theta^{*}}\right) .
\end{aligned}
$$

The term within parentheses in Eq. (A83),

$$
\frac{\frac{\partial \operatorname{Pr}\left(S_{2}^{\star} \mid \mathbb{1}_{S_{1}}\right)}{\partial \theta^{*}}}{\alpha \operatorname{Pr}\left(S_{1}^{\star}\right)-F_{E}}-\frac{\alpha \operatorname{Pr}\left(S_{2}^{\star} \mid \mathbb{1}_{S_{1}}\right)-F_{E}}{\left(\alpha \operatorname{Pr}\left(S_{1}^{\star}\right)-F_{E}\right)^{2}} \frac{\partial \operatorname{Pr}\left(S_{1}^{\star}\right)}{\partial \theta^{*}},
$$

is signed by the expression,

$$
\frac{\frac{\partial \operatorname{Pr}\left(S_{2}^{\star} \mid \mathbb{1}_{S_{1}}\right)}{\partial \theta^{*}}}{\frac{\partial \operatorname{Pr}\left(S_{1}^{\star}\right)}{\partial \theta^{*}}}-\frac{\alpha \operatorname{Pr}\left(S_{2}^{\star} \mid \mathbb{1}_{S_{1}}\right)-F_{E}}{\alpha \operatorname{Pr}\left(S_{1}^{\star}\right)-F_{E}} .
$$

Because the expression in Eq. (A85) is partially obtained by dividing through by $\frac{\partial \operatorname{Pr}\left(S_{1}^{\star}\right)}{\partial \theta^{*}} \leq 0$ and $\frac{\partial \operatorname{Pr}\left(S_{1}^{\star}\right)}{\partial \theta^{*}} \leq 0$, then if the expression in Eq. (A85) is positive, the term in parentheses from Eq. (A83) is negative. If the expression in Eq. (A85) is negative, the opposite relation holds. Clearly, for $\operatorname{Pr}\left(S_{2}^{\star} \mid \mathbb{1}_{S_{1}}\right)=\operatorname{Pr}\left(S_{2}^{\star} \mid 1\right)$, the analysis is trivial since the expression in Eq. (A85) is weakly negative for all parameters. Thus, the sign on $\frac{\partial \Delta K(1)}{\partial \varphi}$ with $\varphi \in\left\{c, F_{P}, \eta\right\}$ is the same as the sign on $\frac{\partial \theta^{*}}{\partial \varphi}$.

For $\operatorname{Pr}\left(S_{2}^{\star} \mid \mathbb{1}_{S_{1}}\right)=\operatorname{Pr}\left(S_{2}^{\star} \mid 0\right)$, the expression in Eq. (A85) is given by,

$$
\frac{\frac{\partial \operatorname{Pr}\left(S_{1}^{\star}\right)}{\partial \theta^{*}}\left(\frac{\alpha \operatorname{Pr}\left(S_{1}^{\star}\right)-F_{E} \theta^{*}}{\operatorname{Pr}\left(S_{1}^{\star}\right)\left(\alpha-F_{E}\right)}+\frac{F_{E} \int_{\theta^{*}}^{1} \theta^{2} g(\theta) \mathrm{d} \theta}{\operatorname{Pr}\left(S_{1}^{\star}\right)^{2}\left(\alpha-F_{E}\right)}\right)}{\frac{\partial \operatorname{Pr}\left(S_{1}^{\star}\right)}{\partial \theta^{*}}}-\frac{\alpha \operatorname{Pr}\left(S_{2}^{\star} \mid 0\right)-F_{E}}{\alpha \operatorname{Pr}\left(S_{1}^{\star}\right)-F_{E}} .
$$

The expression simplifies to,

$$
\frac{\alpha \operatorname{Pr}\left(S_{1}^{\star}\right)+F_{E}\left(\operatorname{Pr}\left(S_{2}^{\star} \mid 1\right)-\theta^{*}\right)}{\operatorname{Pr}\left(S_{1}^{\star}\right)\left(\alpha-F_{E}\right)}-\frac{\alpha \operatorname{Pr}\left(S_{2}^{\star} \mid 0\right)-F_{E}}{\alpha \operatorname{Pr}\left(S_{1}^{\star}\right)-F_{E}} .
$$

Note that $\frac{\alpha \operatorname{Pr}\left(S_{1}^{\star}\right)+F_{E}\left(\operatorname{Pr}\left(S_{2}^{\star} \mid 1\right)-\theta^{*}\right)}{\operatorname{Pr}\left(S_{1}^{\star}\right)\left(\alpha-F_{E}\right)}$ is increasing in $F_{E}$ and in the limit,

$$
\lim _{F_{E} \rightarrow 0} \frac{\alpha \operatorname{Pr}\left(S_{1}^{\star}\right)+F_{E}\left(\operatorname{Pr}\left(S_{2}^{\star} \mid 1\right)-\theta^{*}\right)}{\operatorname{Pr}\left(S_{1}^{\star}\right)\left(\alpha-F_{E}\right)}=1,
$$


while

$$
\frac{\alpha \operatorname{Pr}\left(S_{2}^{\star} \mid 0\right)-F_{E}}{\alpha \operatorname{Pr}\left(S_{1}^{\star}\right)-F_{E}} \leq 1
$$

for all $F_{E}$. Therefore, the expression in Eq. (A87) is weakly positive. Thus, the sign on $\frac{\partial \Delta K(0)}{\partial \varphi}$ with $\varphi \in\left\{c, F_{P}, \eta\right\}$ is the opposite as the $\operatorname{sign}$ on $\frac{\partial \theta^{*}}{\partial \varphi}$.

Now consider the comparative statics of $\Delta K\left(\mathbb{1}_{S_{1}}\right)$ with respect to $\alpha$ and $F_{E}$. Beginning with $\alpha$,

$$
\begin{aligned}
\frac{\partial \Delta K\left(\mathbb{1}_{S_{1}}\right)}{\partial \alpha} & =\frac{\partial}{\partial \alpha}\left(\frac{\alpha \operatorname{Pr}\left(S_{2}^{\star} \mid \mathbb{1}_{S_{1}}\right)-F_{E}}{\alpha \operatorname{Pr}\left(S_{1}^{\star}\right)-F_{E}}-1\right) \\
& =\alpha \frac{\partial \theta^{*}}{\partial \alpha}\left(\frac{\frac{\partial \operatorname{Pr}\left(S_{2}^{\star} \mid \mathbb{I}_{S_{1}}\right)}{\partial \theta^{*}}}{\alpha \operatorname{Pr}\left(S_{1}^{\star}\right)-F_{E}}-\frac{\alpha \operatorname{Pr}\left(S_{2}^{\star} \mid \mathbb{1}_{S_{1}}\right)-F_{E}}{\left(\alpha \operatorname{Pr}\left(S_{1}^{\star}\right)-F_{E}\right)^{2}} \frac{\partial \operatorname{Pr}\left(S_{1}^{\star}\right)}{\partial \theta^{*}}\right) \\
& +\frac{F_{E}\left(\operatorname{Pr}\left(S_{1}^{\star}\right)-\operatorname{Pr}\left(S_{2}^{\star} \mid \mathbb{1}_{S_{1}}\right)\right)}{\left(\alpha \operatorname{Pr}\left(S_{1}^{\star}\right)-F_{E}\right)^{2}} .
\end{aligned}
$$

As $F_{E}$ gets small, the comparative static largely depends on the sign of $\frac{\partial \theta^{*}}{\partial \alpha}$ which is equivocal and largely depends on whether or not $K_{2}(0)$ is greater than zero. For a more in-depth discussion see the Proof of Proposition 1. A similar analysis shows that the sign on $\frac{\partial \Delta K\left(\mathbb{1}_{S_{1}}\right)}{\partial F_{E}}$ is ambiguous.

\section{Proof of Lemma 4:}

The proof follows the proof of Lemma 1.

\section{Proof of Lemma 5:}

The profit function for a fund with type $\theta$ is given by,

$$
\Pi\left(\mathrm{a}_{j}, \theta_{j}\right)= \begin{cases}\left(F_{E}+F_{P}\right)\left(K_{1}+K_{2}(0)\right) & \text { if } \mathrm{a}_{j}=A \\ K_{1}\left(F_{E}+F_{P}+\frac{\theta \lambda \alpha}{1+\eta K_{1}}\right)+\frac{K_{2}(1) \theta}{1+\eta K_{1}}\left(F_{E}+F_{P}+\frac{\theta \lambda \alpha}{1+\eta K_{2}(1)}\right) & \\ +K_{2}(0)\left(1-\frac{\theta}{1+\eta K_{1}}\right)\left(F_{E}+F_{P}+\frac{\theta \lambda \alpha}{1+\eta K_{2}(0)}\right)-c & \text { if } \mathrm{a}_{j}=A .\end{cases}
$$

Using Eq. (A92), define $\Delta^{\lambda}(\theta)$ as a benefit-cost function for a fund with type $\theta$,

$$
\begin{aligned}
\Delta^{\lambda}\left(\theta_{j}\right) & \equiv \Pi\left(A, \theta_{j}\right)-\Pi\left(A, \theta_{j}\right) \\
& =K_{1} \frac{\theta \lambda \alpha}{1+\eta K_{1}}+\frac{K_{2}(1) \theta}{1+\eta K_{1}}\left(\frac{\theta \lambda \alpha}{1+\eta K_{2}(1)}\right)+\frac{\theta\left(K_{2}(1)-K_{2}(0)\right)\left(F_{E}+F_{P}\right)}{1+\eta K_{1}} \\
& +K_{2}(0)\left(1-\frac{\theta}{1+\eta K_{1}}\right)\left(\frac{\theta \lambda \alpha}{1+\eta K_{2}(0)}\right)-c .
\end{aligned}
$$


If an internal threshold exists, it is implicitly defined by $\Delta^{\lambda}\left(\theta^{\lambda}\right)=0$, otherwise $\theta^{\lambda}=1$. Consider that $\theta^{\lambda}$ is an internal value. The expression in Eq. (A94) equals zero at,

$$
\begin{aligned}
0 & =K_{1} \frac{\theta^{\lambda} \lambda \alpha}{1+\eta K_{1}}+\frac{K_{2}(1) \theta^{\lambda}}{1+\eta K_{1}}\left(\frac{\theta^{\lambda} \lambda \alpha}{1+\eta K_{2}(1)}\right)+\frac{\theta^{\lambda}\left(K_{2}(1)-K_{2}(0)\right)\left(F_{E}+F_{P}\right)}{1+\eta K_{1}} \\
& +K_{2}(0)\left(1-\frac{\theta^{\lambda}}{1+\eta K_{1}}\right)\left(\frac{\theta^{\lambda} \lambda \alpha}{1+\eta K_{2}(0)}\right)-c .
\end{aligned}
$$

Define

$$
\begin{aligned}
& x \equiv \frac{1}{1+\eta K_{1}} \\
& y \equiv \frac{1}{1+\eta K_{2}(1)} \\
& z \equiv \frac{1}{1+\eta K_{2}(0)},
\end{aligned}
$$

and note that $y \leq x \leq z$. The expression becomes,

$$
\begin{aligned}
0 & =\theta^{\lambda} x K_{1} \lambda \alpha+\theta^{\lambda^{2}} x K_{2}(1) y \lambda \alpha+\theta^{\lambda} x\left(K_{2}(1)-K_{2}(0)\right)\left(F_{E}+F_{P}\right) \\
& +\theta^{\lambda} z \lambda \alpha K_{2}(0)-\theta^{\lambda^{2}} x K_{2}(0) z \lambda \alpha-c
\end{aligned}
$$

The preceding expression is reordered as,

$$
0=\theta^{\lambda^{2}} \underbrace{x \lambda \alpha\left(y K_{2}(1)-z K_{2}(0)\right)}_{a}+\theta^{\lambda} \underbrace{\left(\left(F_{E}+F_{P}\right) x\left(K_{2}(1)-K_{2}(0)\right)+\lambda \alpha x K_{1}+\lambda \alpha z K_{2}(0)\right)}_{b}-\underbrace{c}_{c} .
$$

The quadratic formula yields,

$$
\begin{aligned}
\theta^{\lambda} & =-\frac{\left(F_{E}+F_{P}\right) x\left(K_{2}(1)-K_{2}(0)\right)+\lambda \alpha x K_{1}+\lambda \alpha z K_{2}(0)}{2 x \lambda \alpha\left(y K_{2}(1)-z K_{2}(0)\right)} \\
& \pm \frac{\sqrt{\left(\left(F_{E}+F_{P}\right) x\left(K_{2}(1)-K_{2}(0)\right)+\lambda \alpha x K_{1}+\lambda \alpha z K_{2}(0)\right)^{2}+4 x \lambda \alpha\left(y K_{2}(1)-z K_{2}(0)\right) c}}{2 x \lambda \alpha\left(y K_{2}(1)-z K_{2}(0)\right)}
\end{aligned}
$$

Consider the first term in the quadratic formula above (and notice the negative sign drops when 
one switches the term of the denominator to $\left(z K_{2}(0)-y K_{2}(1)\right)$ instead of $\left.\left(y K_{2}(1)-z K_{2}(0)\right)\right)$,

$$
\begin{aligned}
\frac{\left(F_{E}+F_{P}\right) x\left(K_{2}(1)-K_{2}(0)\right)+\lambda \alpha x K_{1}+\lambda \alpha z K_{2}(0)}{2 x \lambda \alpha\left(z K_{2}(0)-y K_{2}(1)\right)} & =\underbrace{\frac{\left(F_{E}+F_{P}\right)\left(K_{2}(1)-K_{2}(0)\right)}{2 \lambda \alpha\left(z K_{2}(0)-y K_{2}(1)\right)}}_{\leq 0} \\
& +\underbrace{\frac{K_{1}}{2\left(z K_{2}(0)-y K_{2}(1)\right)}}_{\leq 0} \\
& +\underbrace{\frac{z K_{2}(0)}{2 x\left(z K_{2}(0)-y K_{2}(1)\right)}}_{\leq 0} \\
& \leq 0, \quad
\end{aligned}
$$

because

$$
\begin{aligned}
z K_{2}(0)-y K_{2}(1) & =\frac{K_{2}(0)}{1+\eta K_{2}(0)}-\frac{K_{2}(1)}{1+\eta K_{2}(1)} \\
& \leq 0 .
\end{aligned}
$$

Therefore, if an internal solution exists, it is unique and it must be implicitly defined by,

$$
\begin{aligned}
\theta^{\lambda} & =-\frac{\left(F_{E}+F_{P}\right) x\left(K_{2}(1)-K_{2}(0)\right)+\lambda \alpha x K_{1}+\lambda \alpha z K_{2}(0)}{2 x \lambda \alpha\left(y K_{2}(1)-z K_{2}(0)\right)} \\
& +\frac{\sqrt{\left(\left(F_{E}+F_{P}\right) x\left(K_{2}(1)-K_{2}(0)\right)+\lambda \alpha x K_{1}+\lambda \alpha z K_{2}(0)\right)^{2}+4 x \lambda \alpha\left(y K_{2}(1)-z K_{2}(0)\right) c}}{2 x \lambda \alpha\left(y K_{2}(1)-z K_{2}(0)\right)} .
\end{aligned}
$$

\section{Proof of Lemma 6:}

To prove the lemma, we consider the local change in $\theta^{\lambda}$ in the limiting case when $\lambda=0$. Define

$$
\begin{aligned}
\Psi^{\lambda}(\hat{\theta}) & \equiv \frac{K_{1}(\hat{\theta}) \hat{\theta} \lambda \alpha}{1+\eta K_{1}(\hat{\theta})}+\frac{K_{2}(1, \hat{\theta}) \hat{\theta}}{1+\eta K_{1}(\hat{\theta})}\left(\frac{\hat{\theta} \lambda \alpha}{1+\eta K_{2}(1, \hat{\theta})}\right)+\frac{\hat{\theta}\left(K_{2}(1, \hat{\theta})-K_{2}(0, \hat{\theta})\right)\left(F_{E}+F_{P}\right)}{1+\eta K_{1}(\hat{\theta})} \\
& +K_{2}(0, \hat{\theta})\left(1-\frac{\hat{\theta}}{1+\eta K_{1}(\hat{\theta})}\right)\left(\frac{\hat{\theta} \lambda \alpha}{1+\eta K_{2}(0, \hat{\theta})}\right)-c
\end{aligned}
$$

where $\Psi^{\lambda}\left(\theta^{\lambda}\right)=0$. The change in $\theta^{\lambda}$ with respect to a change in $\lambda$ is solved for using the implicit function theorem and $\Psi^{\lambda}$,

$$
\frac{\partial \theta^{\lambda}}{\partial \lambda}=-\left.\frac{\partial \Psi^{\lambda} / \partial \lambda}{\partial \Psi^{\lambda} / \partial \hat{\theta}}\right|_{\hat{\theta}=\theta^{\lambda}}
$$


We consider the limiting case in which $\lambda=0$. First consider $\partial \Psi^{\lambda} / \partial \hat{\theta}$,

$$
\begin{aligned}
\left.\frac{\partial \Psi^{\lambda}}{\partial \hat{\theta}}\right|_{\lambda=0} & =\lambda \frac{\partial}{\partial \hat{\theta}}\left(\frac{K_{1}(\hat{\theta}) \hat{\theta} \alpha}{1+\eta K_{1}(\hat{\theta})}\right)+\lambda \frac{\partial}{\partial \hat{\theta}}\left(\frac{K_{2}(1, \hat{\theta}) \hat{\theta}}{1+\eta K_{1}(\hat{\theta})}\left(\frac{\hat{\theta} \alpha}{1+\eta K_{2}(1, \hat{\theta})}\right)\right) \\
& +\frac{\partial}{\partial \hat{\theta}}\left(\frac{\hat{\theta}\left(K_{2}(1, \hat{\theta})-K_{2}(0, \hat{\theta})\right)\left(F_{E}+F_{P}\right)}{1+\eta K_{1}(\hat{\theta})}\right) \\
& +\lambda \frac{\partial}{\partial \hat{\theta}}\left(K_{2}(0, \hat{\theta})\left(1-\frac{\hat{\theta}}{1+\eta K_{1}(\hat{\theta})}\right)\left(\frac{\hat{\theta} \alpha}{1+\eta K_{2}(0, \hat{\theta})}\right)\right) \\
& =\frac{\left(K_{2}(1, \hat{\theta})-K_{2}(0, \hat{\theta})\right)\left(F_{E}+F_{P}\right)}{1+\eta K_{1}(\hat{\theta})}+\frac{\hat{\theta}\left(\frac{\partial K_{2}(1, \hat{\theta})}{\partial \hat{\theta}}-\frac{\partial K_{2}(0, \hat{\theta})}{\partial \hat{\theta}}\right)\left(F_{E}+F_{P}\right)}{1+\eta K_{1}(\hat{\theta})} \\
& -\frac{\hat{\theta} \eta \frac{\partial K_{1}(\hat{\theta})}{\partial \hat{\theta}}\left(K_{2}(1, \hat{\theta})-K_{2}(0, \hat{\theta})\right)\left(F_{E}+F_{P}\right)}{\left(1+\eta K_{1}(\hat{\theta})\right)^{2}} \\
& \geq 0 .
\end{aligned}
$$

Now, consider $\partial \Psi^{\lambda} / \partial \lambda$

$$
\begin{aligned}
\left.\frac{\partial \Psi^{\lambda}}{\partial \lambda}\right|_{\lambda=0} & =\lambda \frac{\partial}{\partial \lambda}\left(\frac{K_{1}(\lambda) \hat{\theta} \alpha}{1+\eta K_{1}(\lambda)}\right)+\lambda \frac{\partial}{\partial \lambda}\left(\frac{K_{2}(1, \lambda) \hat{\theta}}{1+\eta K_{1}(\lambda)}\left(\frac{\hat{\theta} \alpha}{1+\eta K_{2}(1, \lambda)}\right)\right) \\
& +\frac{\partial}{\partial \lambda}\left(\frac{\hat{\theta}\left(K_{2}(1, \lambda)-K_{2}(0, \lambda)\right)\left(F_{E}+F_{P}\right)}{1+\eta K_{1}(\lambda)}\right) \\
& +\lambda \frac{\partial}{\partial \lambda}\left(K_{2}(0, \lambda)\left(1-\frac{\hat{\theta}}{1+\eta K_{1}(\lambda)}\right)\left(\frac{\hat{\theta} \alpha}{1+\eta K_{2}(0, \lambda)}\right)\right) \\
& +\frac{K_{1}(\lambda) \hat{\theta} \alpha}{1+\eta K_{1}(\lambda)}+\frac{K_{2}(1, \lambda) \hat{\theta}}{1+\eta K_{1}(\lambda)}\left(\frac{\hat{\theta} \alpha}{1+\eta K_{2}(1, \lambda)}\right) \\
& +K_{2}(0, \lambda)\left(1-\frac{\hat{\theta}}{1+\eta K_{1}(\lambda)}\right)\left(\frac{\hat{\theta} \alpha}{1+\eta K_{2}(0, \lambda)}\right) .
\end{aligned}
$$

The preceding expression simplifies to,

$$
\begin{aligned}
& \quad=\hat{\theta}\left(\frac{K_{1}(\lambda) \alpha}{1+\eta K_{1}(\lambda)}+\frac{K_{2}(1, \lambda) \hat{\theta}}{1+\eta K_{1}(\lambda)}\left(\frac{\alpha}{1+\eta K_{2}(1, \lambda)}\right)\right. \\
& \left.\quad+K_{2}(0, \lambda)\left(1-\frac{\hat{\theta}}{1+\eta K_{1}(\lambda)}\right)\left(\frac{\alpha}{1+\eta K_{2}(0, \lambda)}\right)\right) \\
& \geq 0 .
\end{aligned}
$$

Therefore at $\lambda=0$,

$$
\left.\frac{\partial \theta^{\lambda}}{\partial \lambda}\right|_{\lambda=0} \leq 0 .
$$


Furthermore, at $\lambda=1, K_{1}=K_{2}(0)=K_{2}(0)=0$ and $1=\left.\theta^{\lambda}\right|_{\lambda=1} \geq\left.\theta^{\lambda}\right|_{\lambda=0}$. Thus, because the functions are continuous in $\lambda$, the comparative static may be non-monotonic in $\lambda$. 


\section{References}

Baker, M., Litov, L., Wachter, J. A., Wurgler, J., 2010. Can mutual fund managers pick stocks? Evidence from their trades prior to earnings announcements. Journal of Financial and Quantitative Analysis 45, 1111-1131.

Ben-David, I., Franzoni, F., Moussawi, R., 2014. Do ETFs increase volatility? Unpublished working paper. Ohio State University.

Berk, J., Green, R., 2004. Mutual fund flows and performance in rational markets. Journal of Political Economy 112, 1269-1295.

Berk, J., van Binsbergen, J., 2015. Measuring skill in the mutual fund industry. Journal of Financial Economics 118, 1-20.

Berk, J., van Binsbergen, J., Liu, B., 2016. Matching capital and labor. Unpublished working paper. Stanford University.

Brown, D. P., Wu, Y., 2014. Mutual fund flows and cross-fund learning within families. Journal of Finance 71, 383-424.

Buffa, A. M., Vayanos, D., Woolley, P., 2014. Asset management contracts and equilibrium prices. Unpublished working paper. Boston University.

Carhart, M. M., 1997. On persistence in mutual fund performance. Journal of Finance 52, 57-82.

Chevalier, J., Ellison, G., 1997. Risk taking by mutual funds as a response to incentives. Journal of Political Economy 105, 1167-1200.

Christoffersen, S. E. K., 2001. Why do money fund managers voluntarily waive their fees? Journal of Finance 56, 1117-1140.

Cremers, M., Petajisto, A., 2009. How active is your fund manager? A new measure that predicts performance. The Review of Financial Studies 22, 3329-3365.

Cuoco, D., Kaniel, R., 2011. Equilibrium prices in the presence of delegated portfolio management. Journal of Financial Economics 101, 264-296.

Da, Z., Shive, S., 2016. Exchange traded funds and asset return correlations. Unpublished working paper. University of Notre Dame. 
Daniel, K., Grinblatt, M., Titman, S., Wermers, R., 1997. Measuring mutual fund performance with characteristics-based benchmarks. Journal of Finance 52, 1035-1058.

Das, S. R., Sundaram, R. K., 2002. Fee speech: Signaling, risk-sharing, and the impact of fee structures on investor welfare. The Review of Financial Studies 15, 1465-1497.

Del Guercio, D., Reuter, J., 2014. Mutual fund performance and the incentive to generate alpha. Journal of Finance 69, 1673-1704.

Fama, E. F., French, K. R., 2010. Luck versus skill in the cross-section of mutual fund returns. Journal of Finance 65, 1915-1947.

French, K. R., 2008. Presidential Address: The cost of active investing. Journal of Finance 63, $1537-1573$.

Fung, W., Hsieh, D. A., Naik, N. Y., Ramadorai, T., 2008. Hedge funds: performance, risk, and capital formation. Journal of Finance 63, 1777-1803.

García, D., Vanden, J. M., 2009. Information acquisition and mutual funds. Journal of Economic Theory 144, 1965-1995.

Heinkel, R., Stoughton, N. M., 1994. The dynamics of portfolio management contracts. The Review of Financial Studies 7, 351-387.

Hoberg, G., Kumar, N., Prabhala, N. R., 2016. Mutual fund competition, managerial skill, and alpha persistence. Unpublished working paper. University of Southern California.

Huang, J., Wei, K. D., Yan, H., 2007. Participation costs and the sensitivity of fund flows to past performance. Journal of Finance 62, 1273-1311.

Ippolito, R. A., 1992. Consumer reaction to measures of poor quality: Evidence from the mutual fund industry. Journal of Law and Economics 35, 45-70.

Israeli, D., Lee, C. M. C., Sridharan, S., 2017. Is there a dark side to exchange traded funds (ETFs)? An information perspective. Review of Accounting Studies Forthcoming.

Jensen, M. C., 1968. The performance of mutual funds in the period 1945-1964. Journal of Finance $23,389-416$. 
Kacperczyk, M., Van Nieuwerburgh, S., Veldkamp, L., 2014. Time-varying fund manager skill. Journal of Finance 69, 1455-1484.

Kacperczyk, M., Sialm, C., Zheng, L., 2005. On the industry concentration of actively managed equity mutual funds. Journal of Finance 60, 1983-2011.

Kacperczyk, M., Sialm, C., Zheng, L., 2008. Unobserved actions of mutual funds. Review of Financial Studies 21, 2379-2416.

Pástor, L., Stambaugh, R. F., 2012. On the size of the active management industry. Journal of Political Economy 120, 740-781.

Pástor, L., Stambaugh, R. F., Taylor, L. A., 2015. Scale and skill in active management. Journal of Financial Economics 116, 23-45.

Pollet, J. M., Wilson, M., 2008. How does size affect mutual fund behavior? Journal of Finance 63, 2941-2969.

Sirri, E. R., Tufano, P., 1998. Costly search and mutual fund flows. Journal of Finance 53, 15891622. 


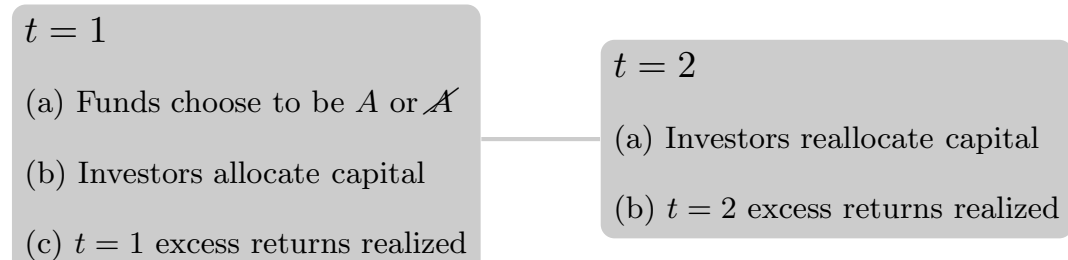

Fig. 1. Model timing. Truly active funds are indicated by $A$ and faux-active funds are indicated by $A$. 


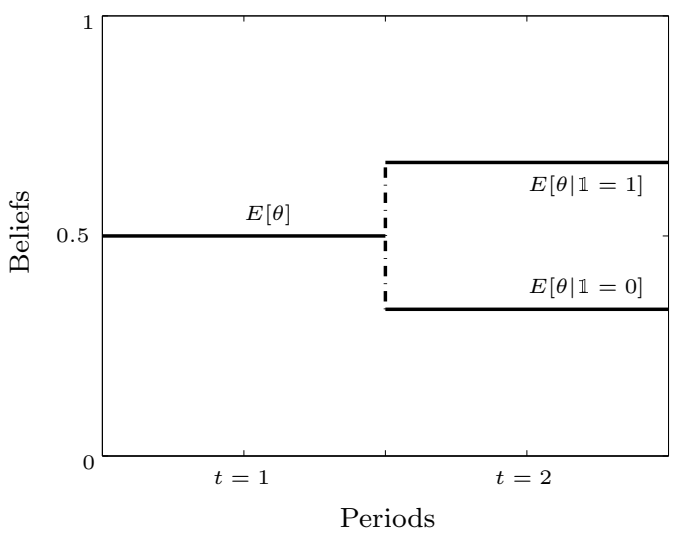

(a) Without moral hazard

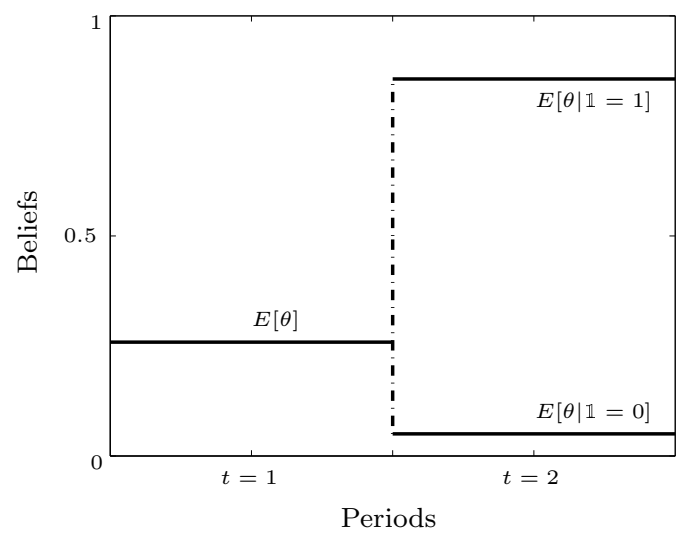

(b) With moral hazard

Fig. 2. Investor beliefs without and with moral hazard. Investors' initial belief regarding $\theta \in[0,1]$ at $t=1$ is depicted in a setting with moral hazard and a setting without. The unconditional belief $E[\theta]$ with moral hazard is strictly lower than the belief without moral hazard. Investors' conditional beliefs based on first-period success are also depicted. The difference between $E\left[\theta \mid \mathbb{1}_{S}=1\right]-E\left[\theta \mid \mathbb{1}_{S}=0\right]$, i.e., fund-flow volatility, is larger with moral hazard than without. 